\title{
Stem Cells and their Applications for the Treatment of Injuries to the Central Nervous System
}

\section{Zahra Nikookar, Majid Hassanpour Ezatti*}

Department of Biology, Faculty of Basic Sciences, Shahed University, Tehran, Iran

\section{ABSTRACT}

Introduction: The most common causes of brain and spinal cord injuries are accidents, falls, sports injuries, and trauma, which can lead to sensory and motor function deficits. Enormous efforts have been made to use stem cells to repair and prevent the development of complications caused by damage to the central nervous system. The main challenge in this field is to select the right stem cells to replace the lost nerve cells and prevent processes that disrupt the function of stem cells. In this review article, current information on various stem cells used in the treatment of damage to the nervous system, the possible mechanisms of their functions have been discussed. Furthermore, advantages and disadvantages of stem cell therapy are described based on the findings of basic and clinical studies. The high cost of stem cell therapy and unwanted side effects are major challenges in using stem cell therapy to repair the nervous system. Thus, more investigations are required to optimize cell therapy approaches in clinical settings. Conclusion: The existence of different types of stem cells with diverse capabilities and solving existing problems can increase the hope of using of stem cell therapy to treat damage to the nervous system.

\section{Keywords:}

1. Spinal Cord Injuries

2. Cell- and Tissue-Based Therapy

3. Stem Cells

*Corresponding Author: Majid Hassanpour Ezatti

Email: Hassanpour@shahed.ac.ir 


\section{سلولهاى بنيادى و كاربرد آنها براى درمان آسيبهاى سيستم عصبى مر كزى}

زهرا نيكو كار، مجيد حسن يور عزتى"

كروه زيست شناسى، دانشكده علوم يايه، دانشكاه شاهد، تهران، ايران

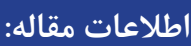

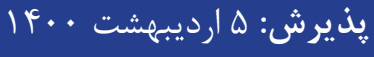

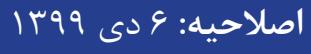

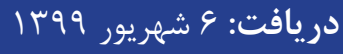

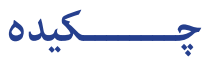

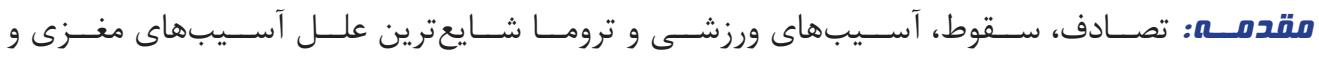

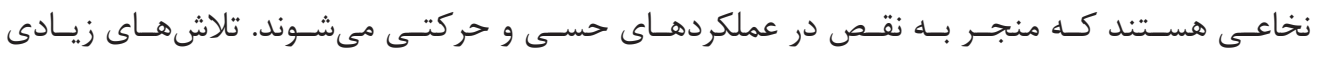

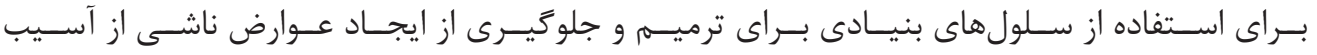

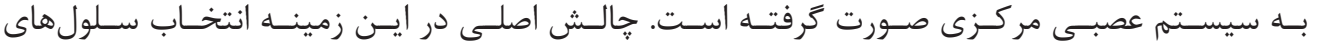

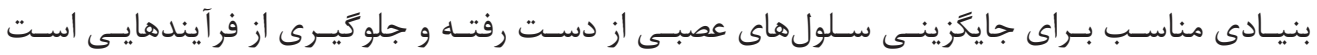

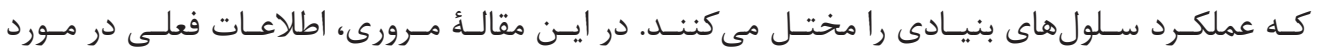

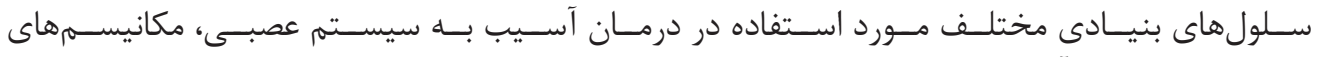

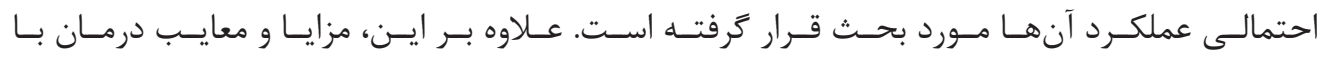

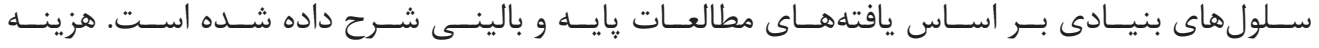

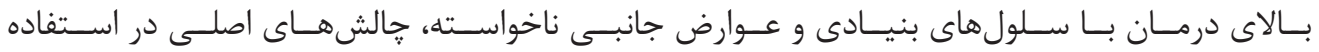

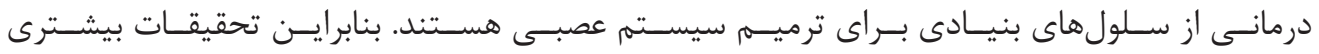

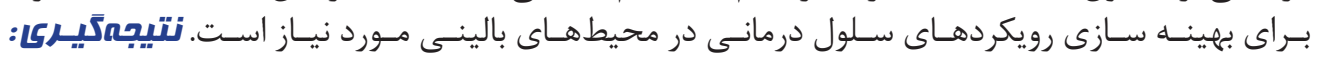

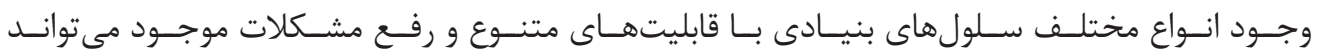

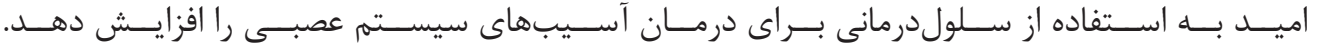

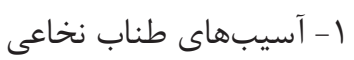

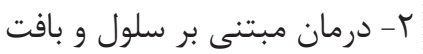

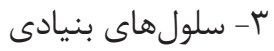




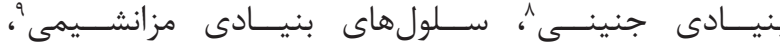

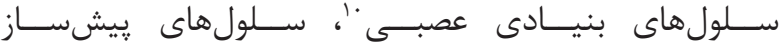

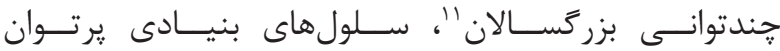

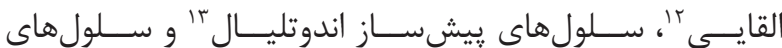

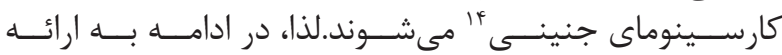

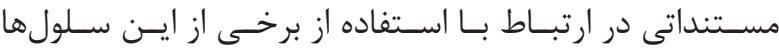

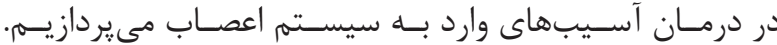

آشناى با سلول هاى بنيادى دري

دو ويزَّى مهـهم سـلولهاى بنيـادى، توانايسى تمايـز بــهـ انـواع

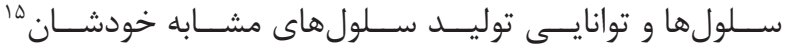

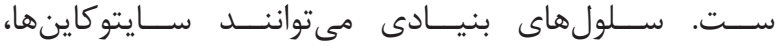

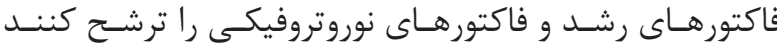

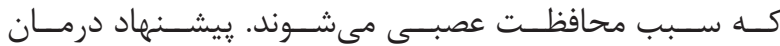

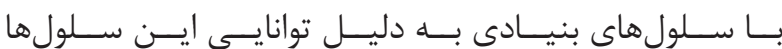

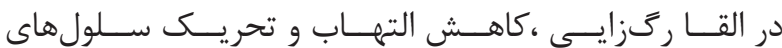

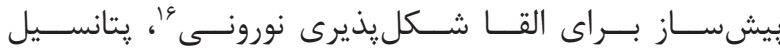

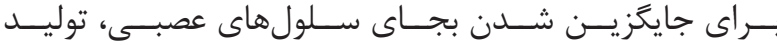

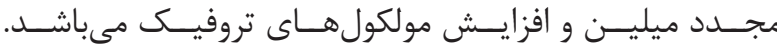

\section{انواع سلولهاى بنيادى}

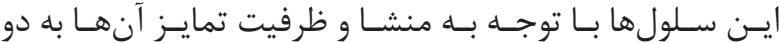

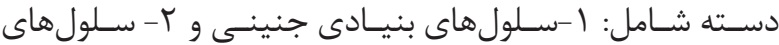

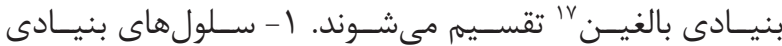

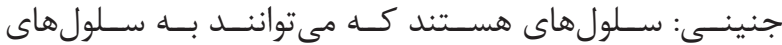

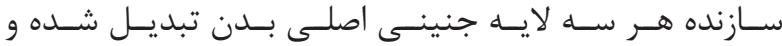

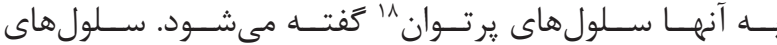

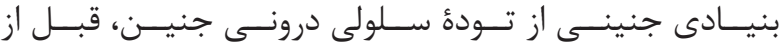

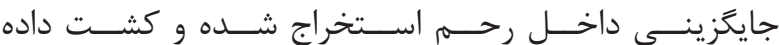

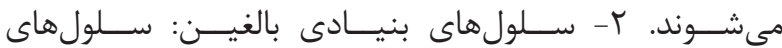

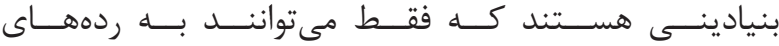

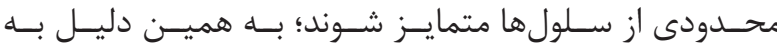

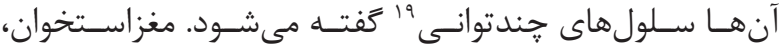

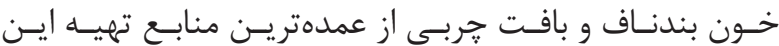

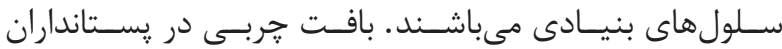

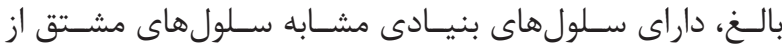

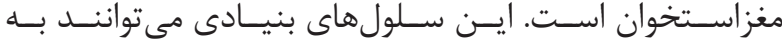

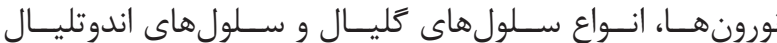

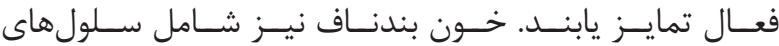

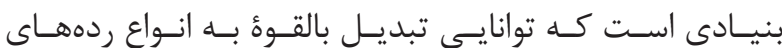

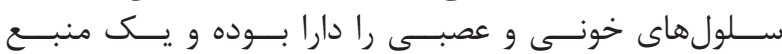
سـلولى در دسـترس و ارزان قيمــت بــه حســاب مى آيـــ (بآ).

${ }^{1}$ Spinal cord injury

${ }^{2}$ Traumatic brain injury

${ }^{3}$ Hyperbaric Oxygen

${ }^{4}$ Blood brain barrier

${ }^{5}$ Exogenous stem cells

${ }^{6}$ Schwann cells

${ }^{7}$ Olfactory Ensheathing cells

${ }^{8}$ Embryonic stem cells

${ }^{9}$ Mesenchymal stem cells

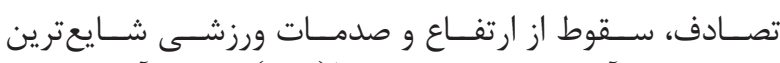

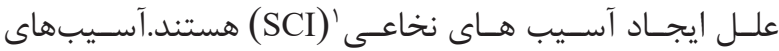

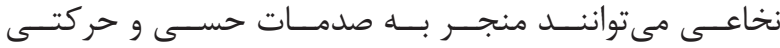

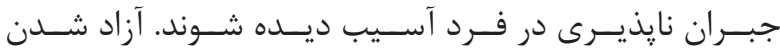

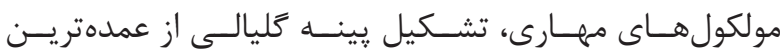

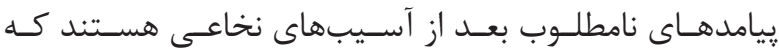

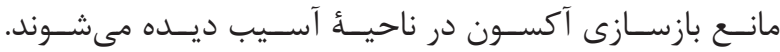

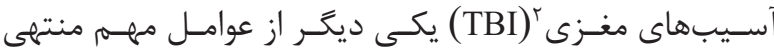

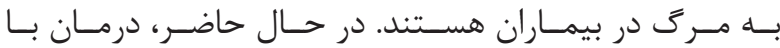

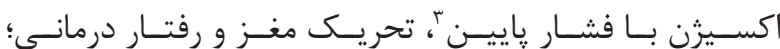

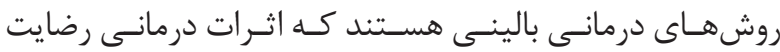

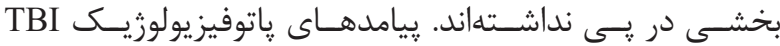

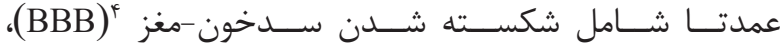

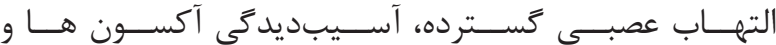

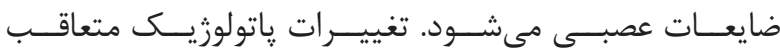

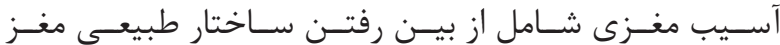

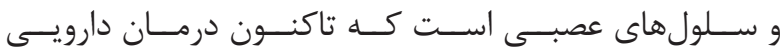

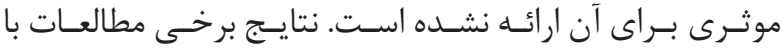

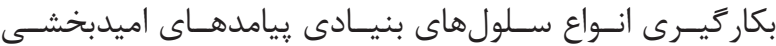

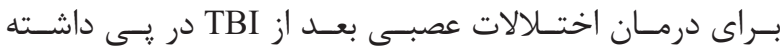

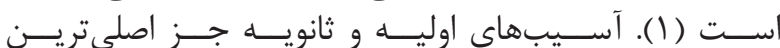

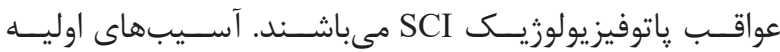

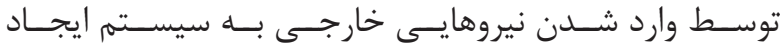

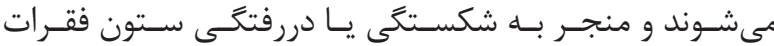

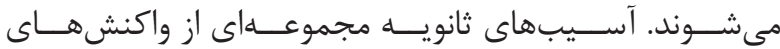

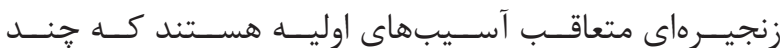

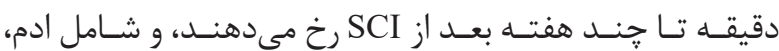

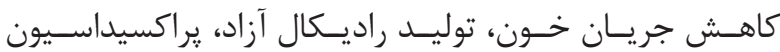

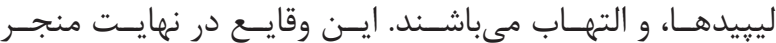

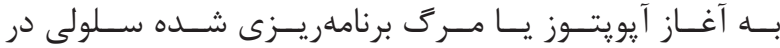

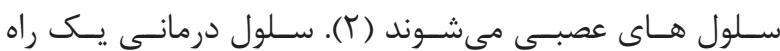

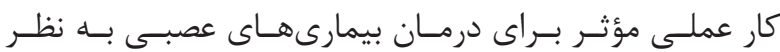

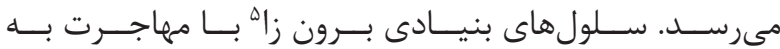

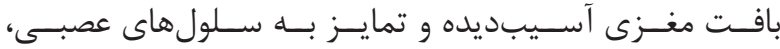

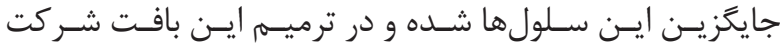

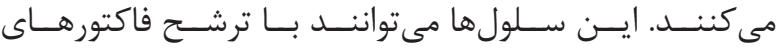

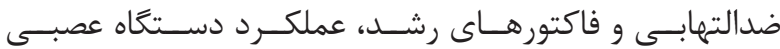

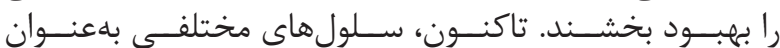

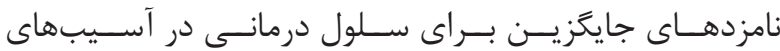

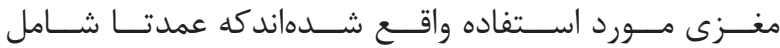

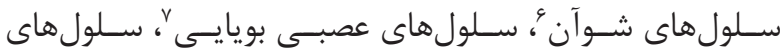

${ }^{10}$ Neural Stem Cells

${ }^{11}$ Multipotent Adult Progenitor Cells

${ }^{12}$ Induced Pluripotent Stem Cells

${ }^{13}$ Endothelial progenitor cells

${ }^{14}$ Embryonal carcinoma cells

${ }^{15}$ Self-renewal

${ }^{16}$ Neuronal plasticity

${ }^{17}$ Adult stem cells

${ }^{18}$ Pluripotent

${ }^{19}$ Multipotent 


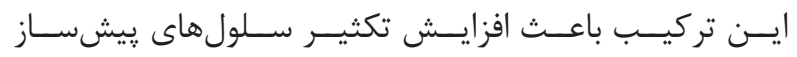

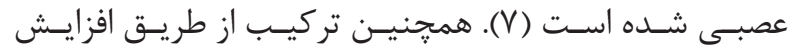

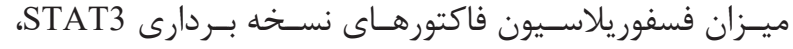

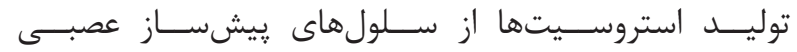

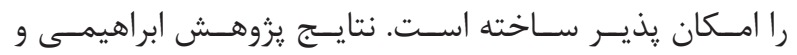

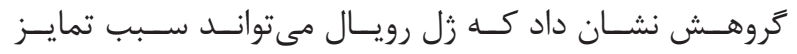

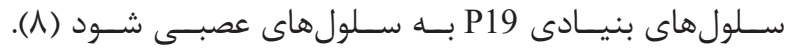

بل - سلولهاى پيشساز جندتوان بالغين (MAPC)

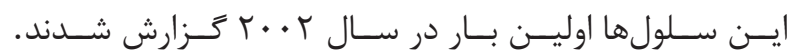

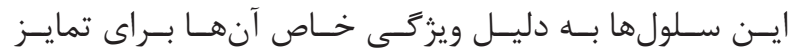

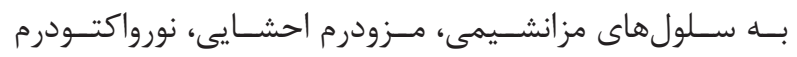

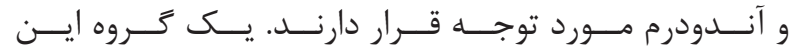

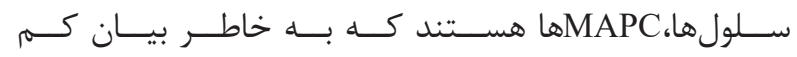

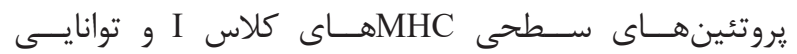

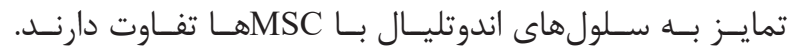

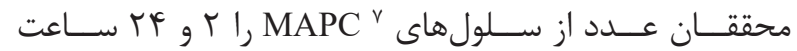

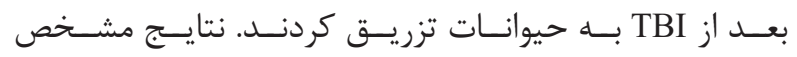

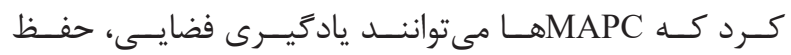

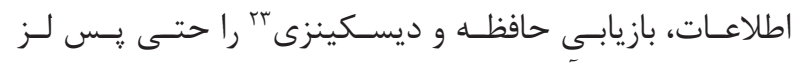

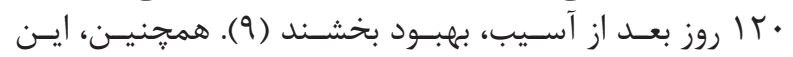

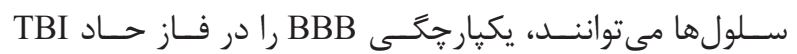

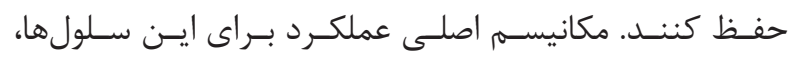

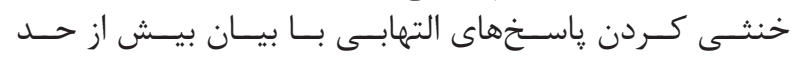

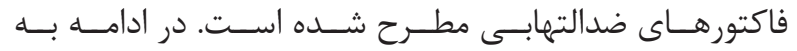

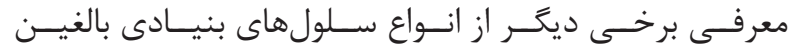

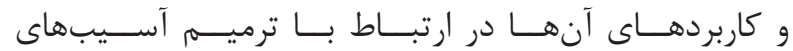

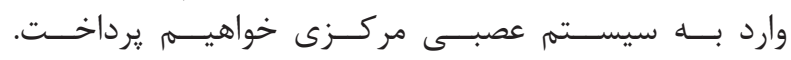

ا - سلولهاى بنيادى مزانشيمى (MSC)

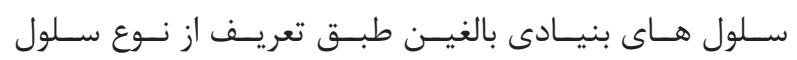

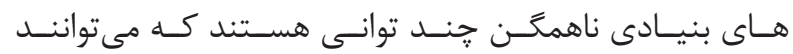

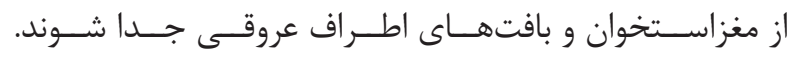

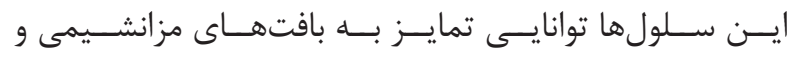

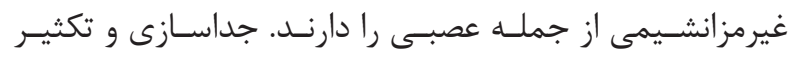

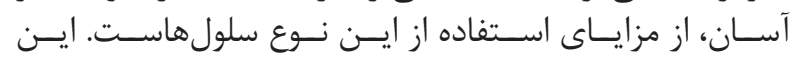

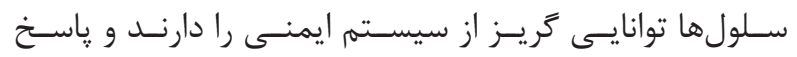

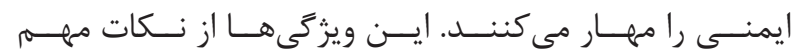

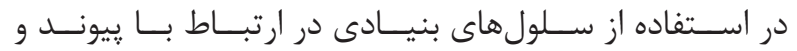

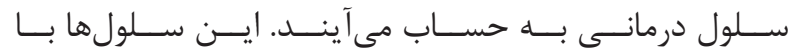

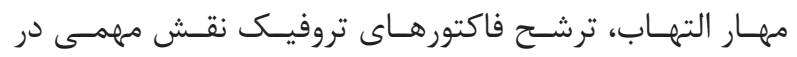

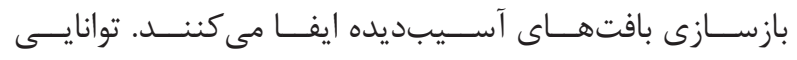

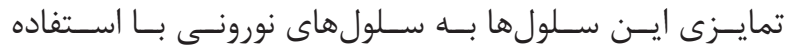

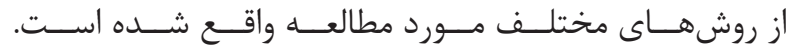

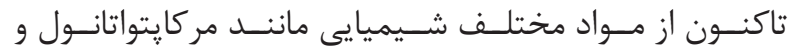

${ }^{20}$ Chou

${ }^{21}$ Martin

\section{الف - سلولهاى بنيادى جنينى إلمادي ا - سلولهاى بنيادى بدست بنيادى آمده از جنين}

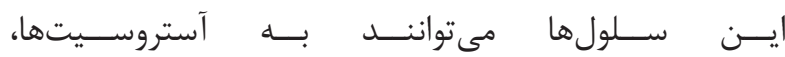

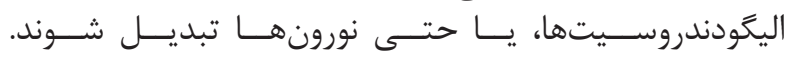

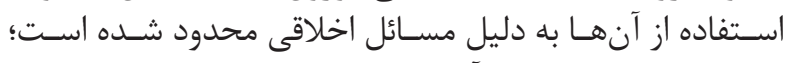

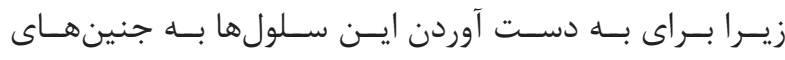

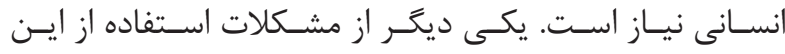

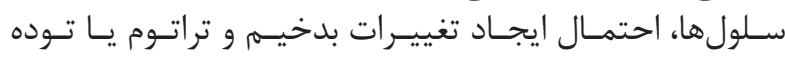

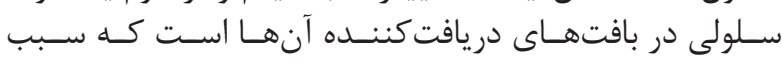

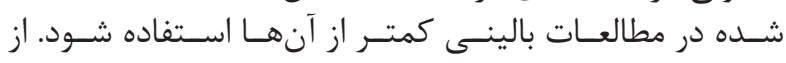

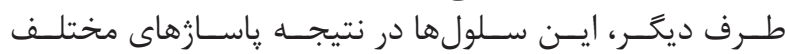

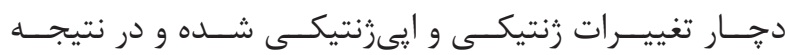

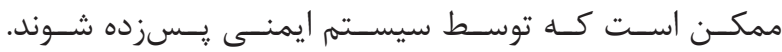

\section{r- سلولهاى كارسينوماى جنينى}

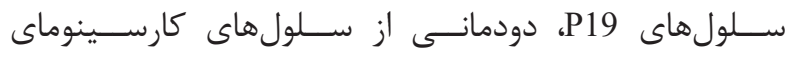

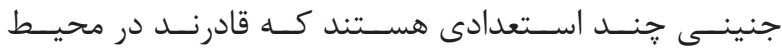

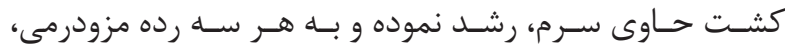

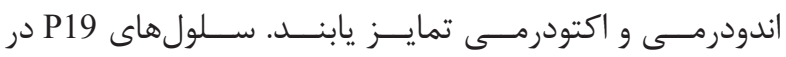

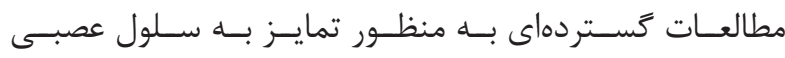

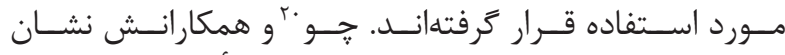

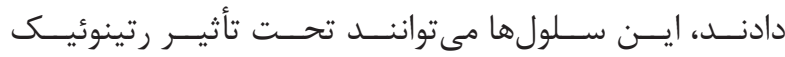

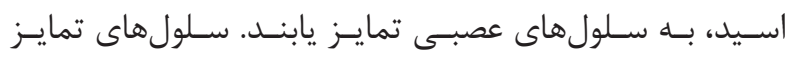

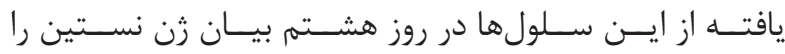

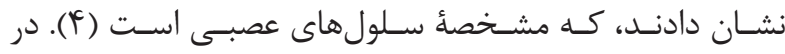

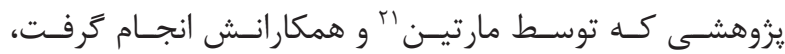

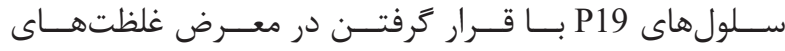

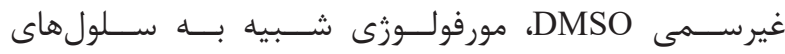

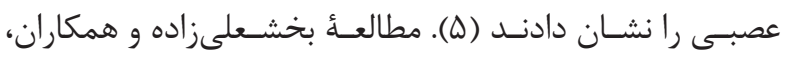

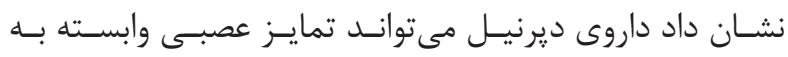

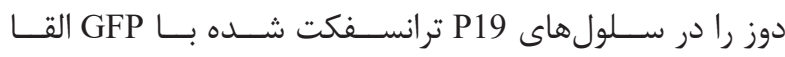

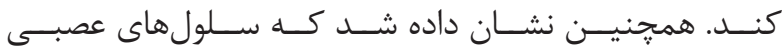

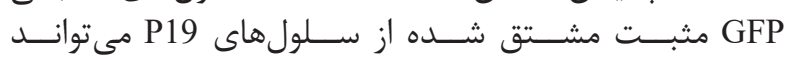

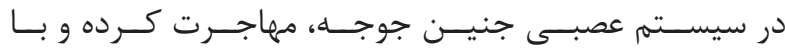

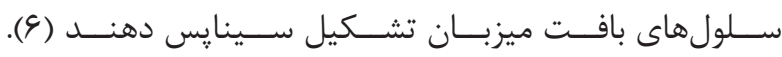

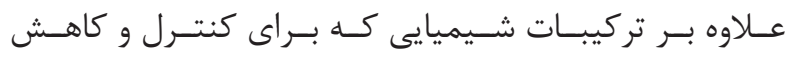

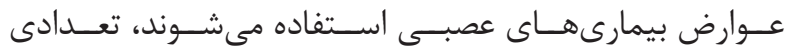

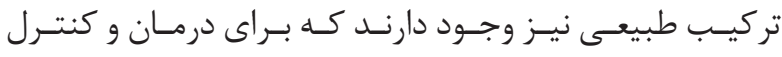

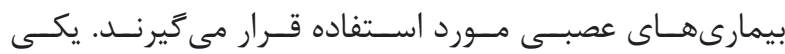

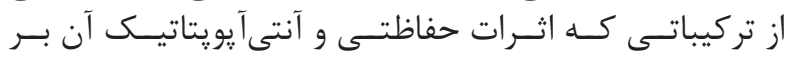

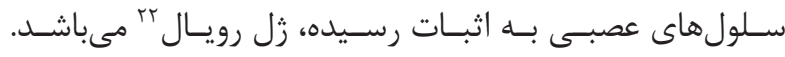

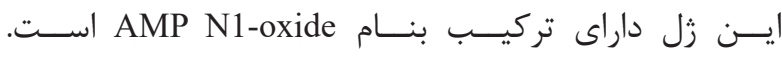

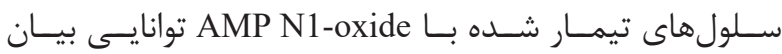
يروتئينهـاى اختصاصسى ســلولهاى عصبـى بالـــ را دارنــد.

\footnotetext{
${ }^{22}$ Royal jelly

${ }^{23}$ Dyskinesia
} 


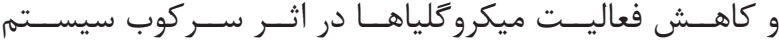

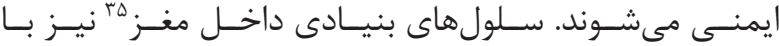

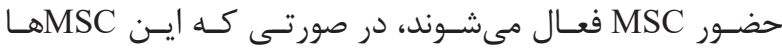

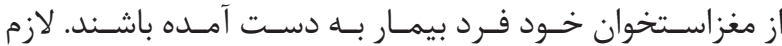

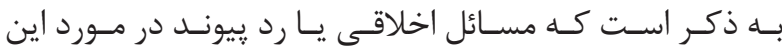

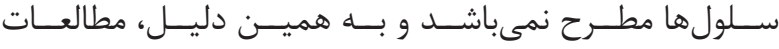

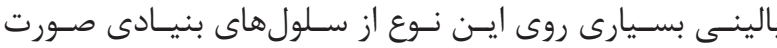

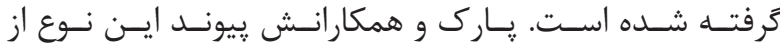

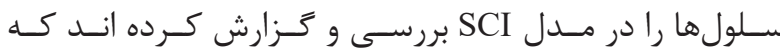

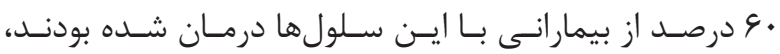

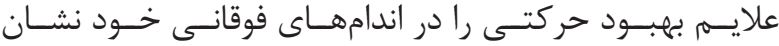

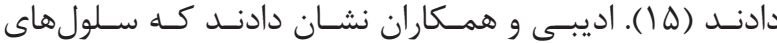

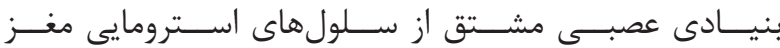

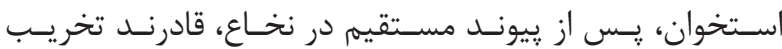

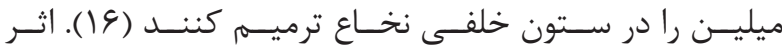

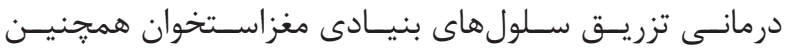

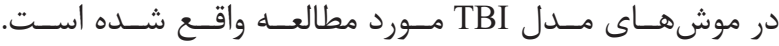

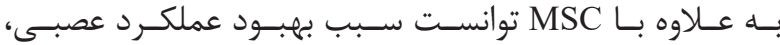

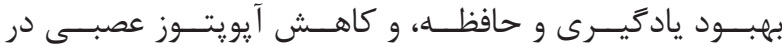

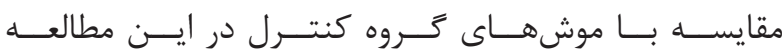

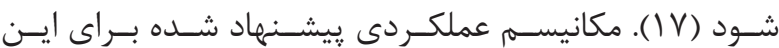

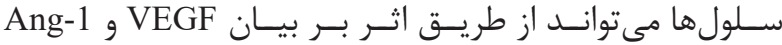

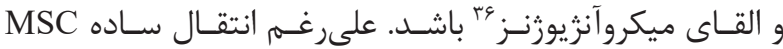

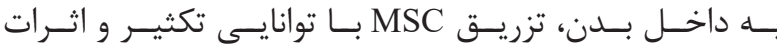

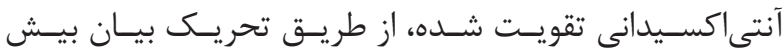

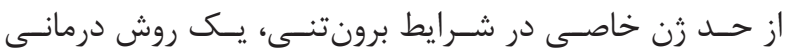

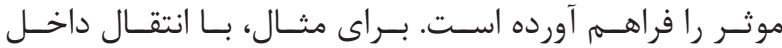
وريـدى MSCهايى كه زن سوريراكسـيد ديسـموتاز ب (SOD2)

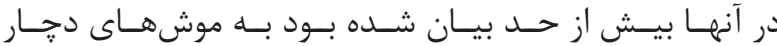
TBI

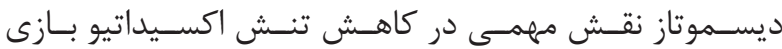

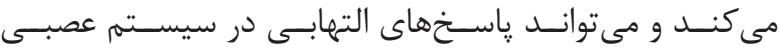

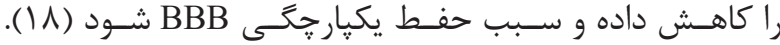

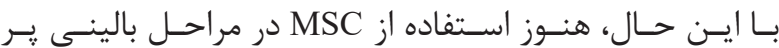

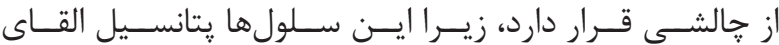

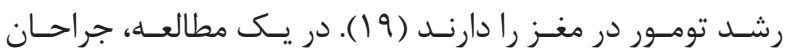

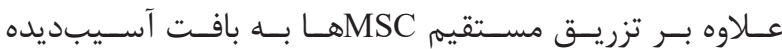

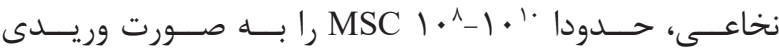

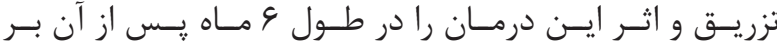

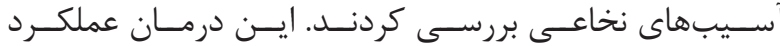

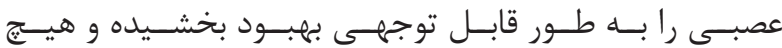

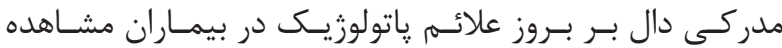

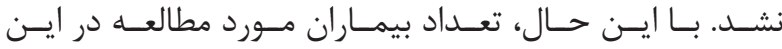

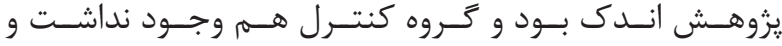

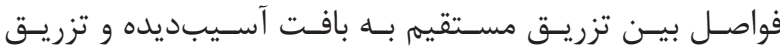

${ }^{24}$ Epidermal Growth Factor

${ }^{25}$ Brain-Derived Neurotrophic Factor

${ }^{26}$ Basic Fibroblast Growth Factor

${ }^{27}$ Platelet-Derived Growth Factor

${ }^{28}$ Sanchez

${ }^{29}$ Woodbury

${ }^{30}$ Intracranial aneurysms

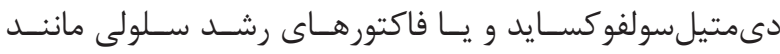

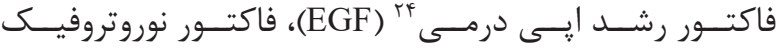

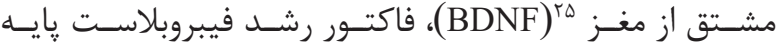

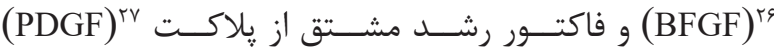

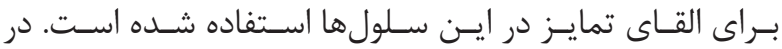

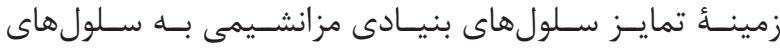

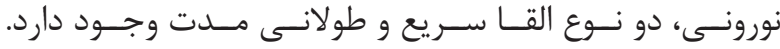

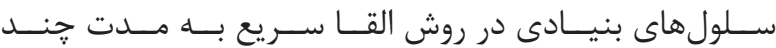

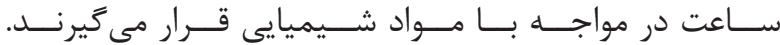

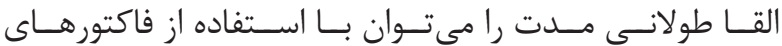

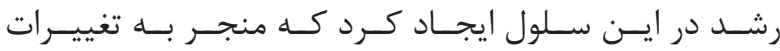

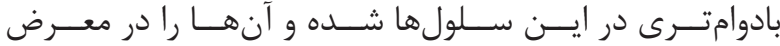

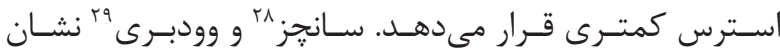

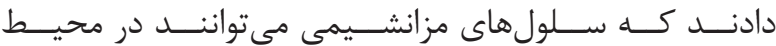

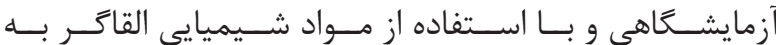

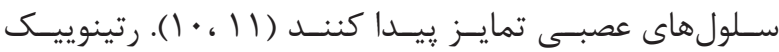

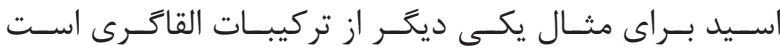

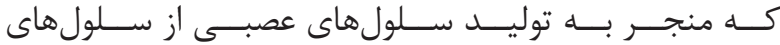

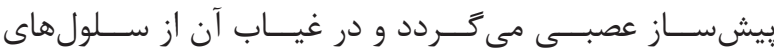

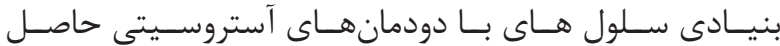

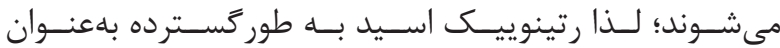

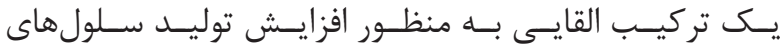

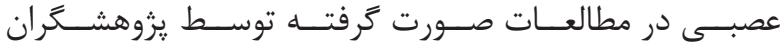

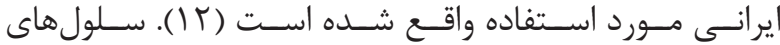

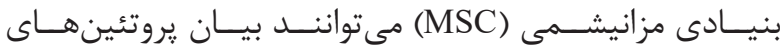

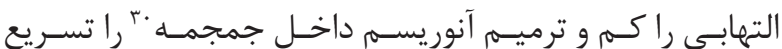

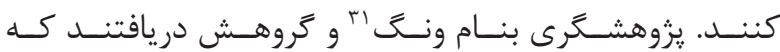

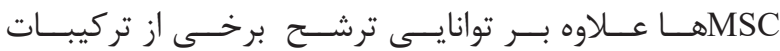

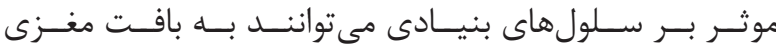

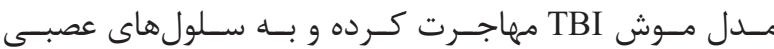

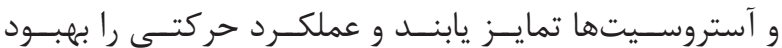

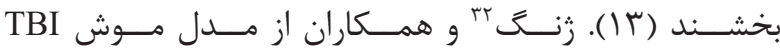

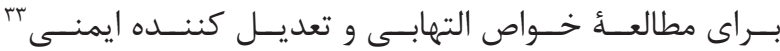

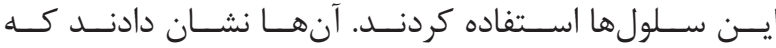

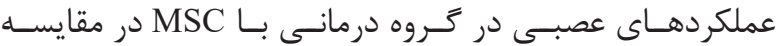

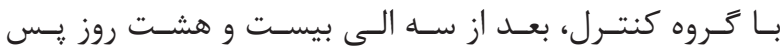

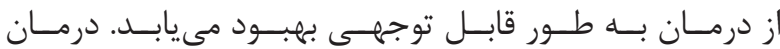

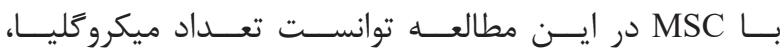

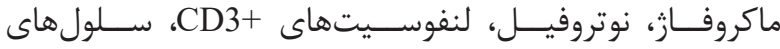

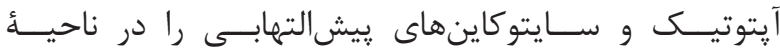

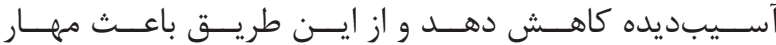

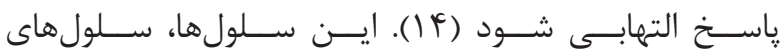

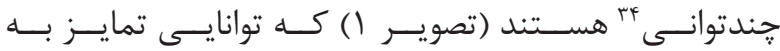

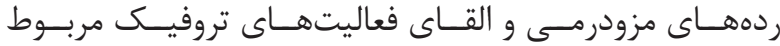

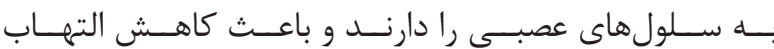

${ }^{31}$ Wang

${ }^{32}$ Zhang

${ }^{33}$ Immunomodulatory

${ }^{34}$ Multipotent

${ }^{35}$ Intramedullary endogenous stem cell

${ }^{36}$ Microangiogenesis

${ }^{37}$ Homing effect 


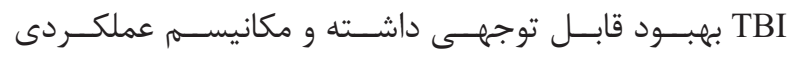

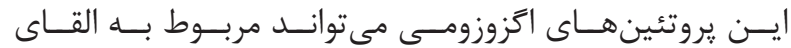

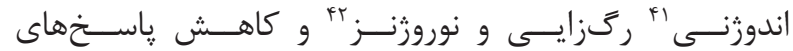

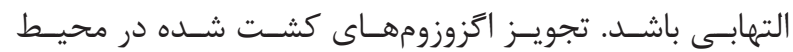

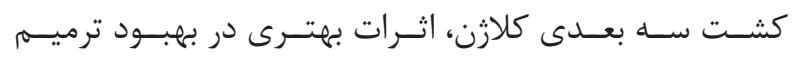

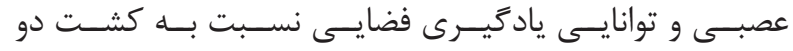

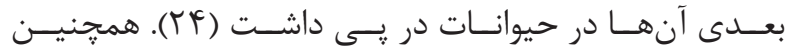

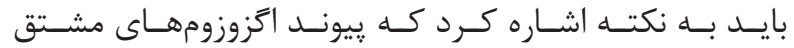

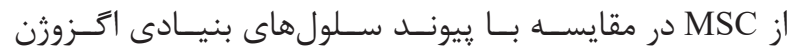

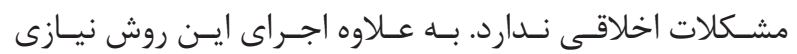

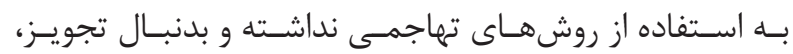

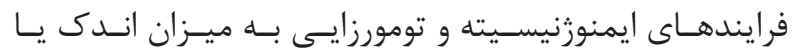

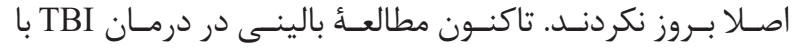

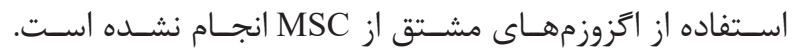

\section{r- - سلولهاى شوآن}

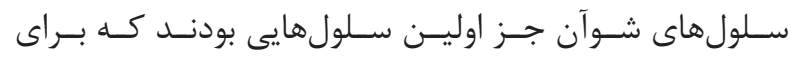

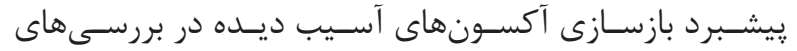

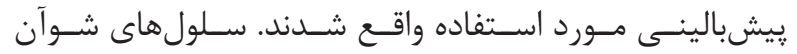

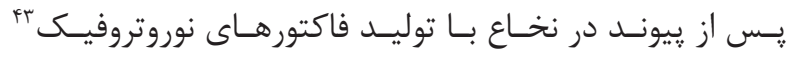

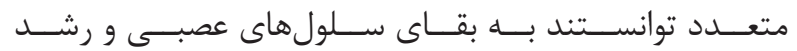

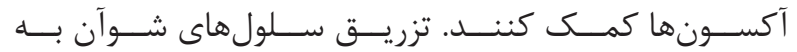

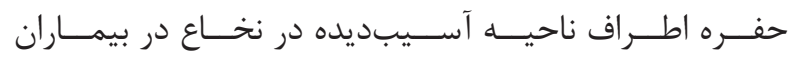

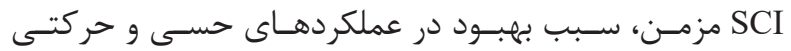

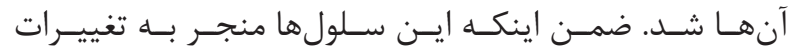

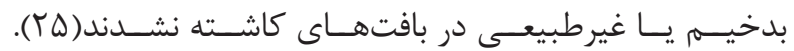

\section{r- سلول هاى عصبى بويايى (OEC)}

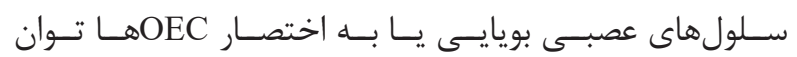

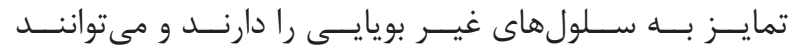

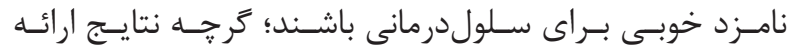

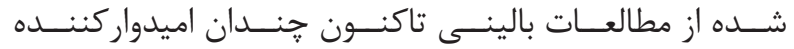

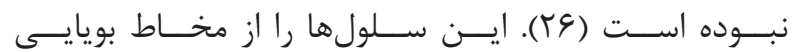

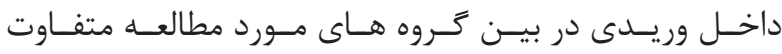

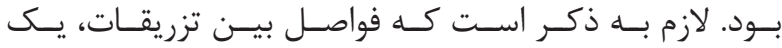

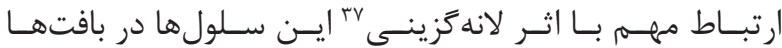

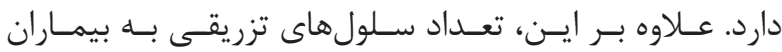

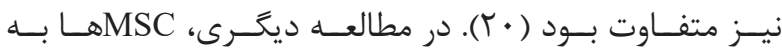

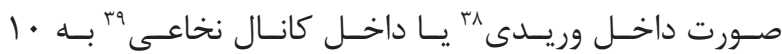

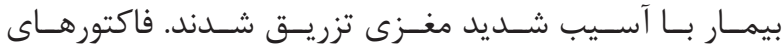

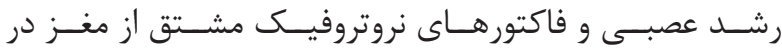

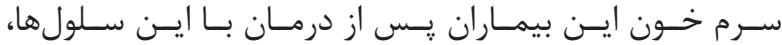

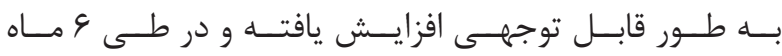

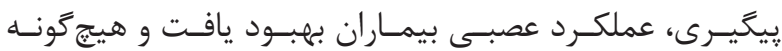

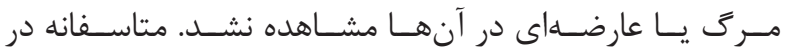

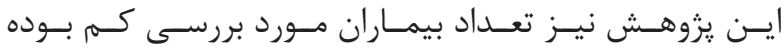

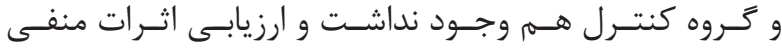

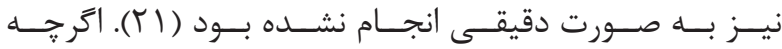

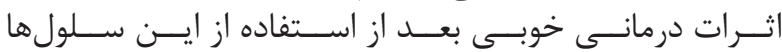

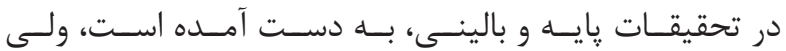

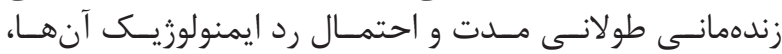

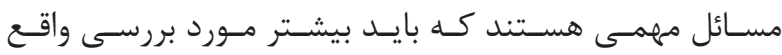

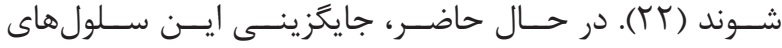

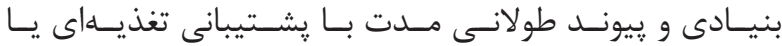

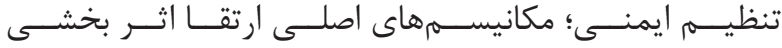

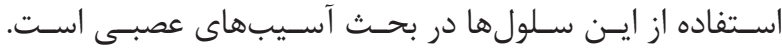

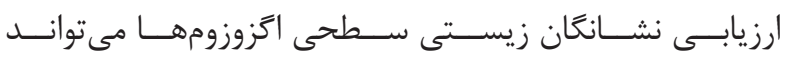

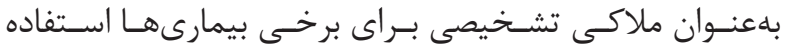

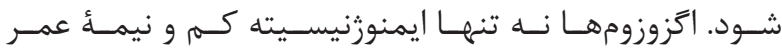

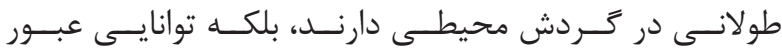

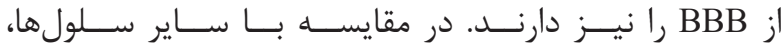

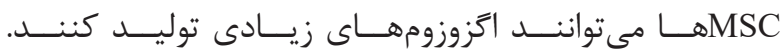

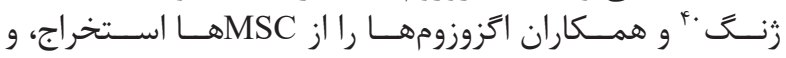

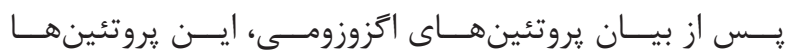

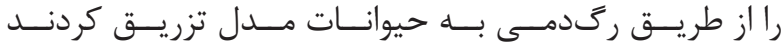

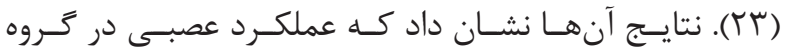

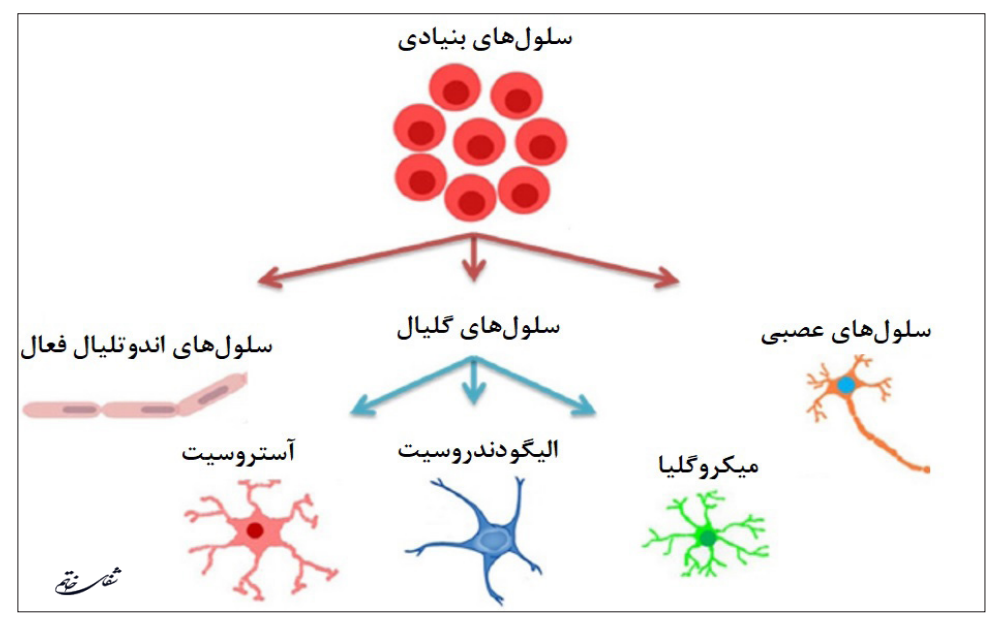

تصوير ا- تمايز سلولهاى بنيادى به انواع سلولهاى بافت عصبى (؟)

${ }^{38}$ Intravenously

${ }^{39}$ Intrathecally

${ }^{40}$ Zhang
${ }^{41}$ Endogenous
${ }^{42}$ Neurogenesis
${ }^{43}$ Neurotrophic factor 


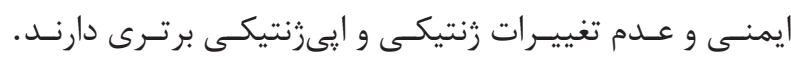

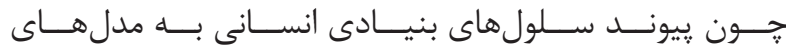

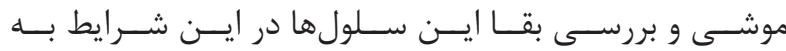

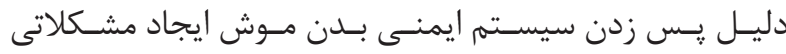

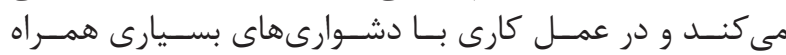

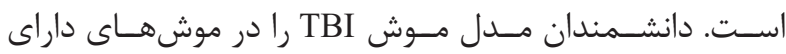

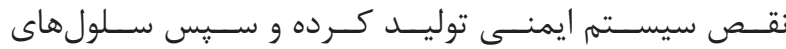

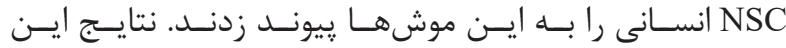

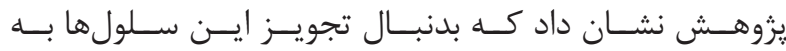

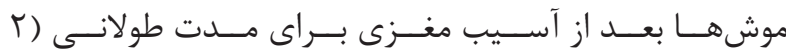

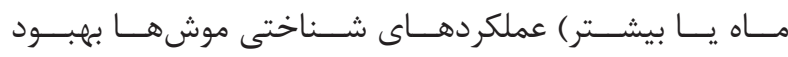

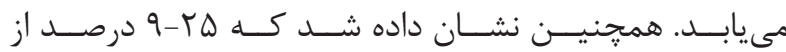

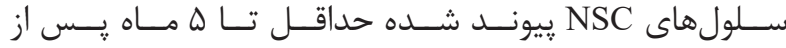

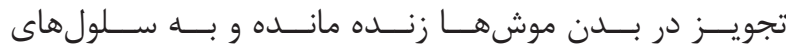

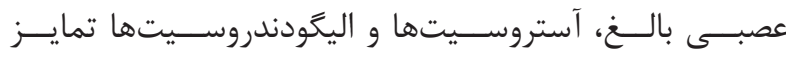

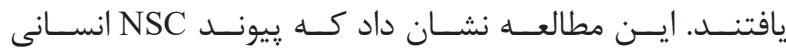

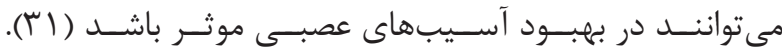

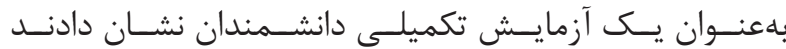

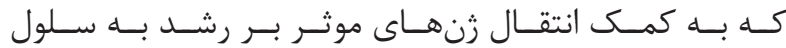

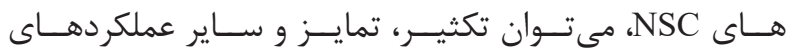

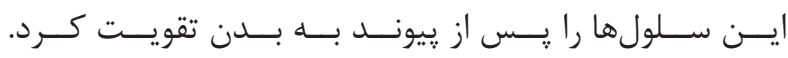

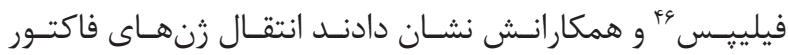

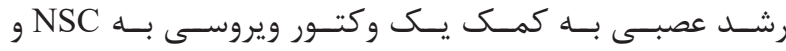

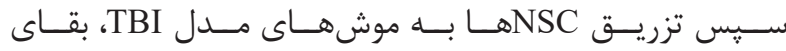

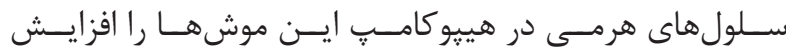

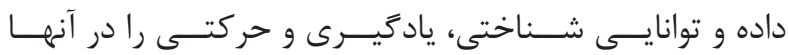

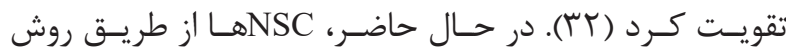

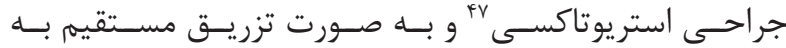

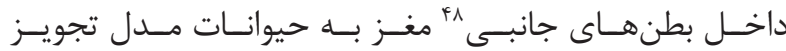

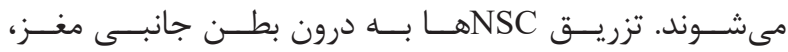

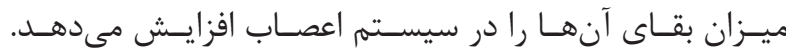

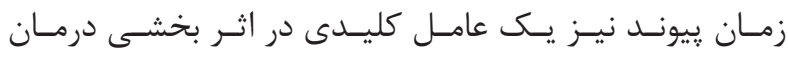

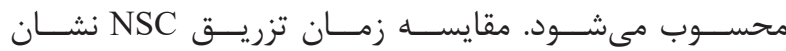

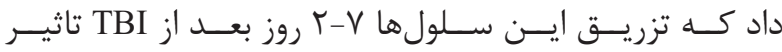

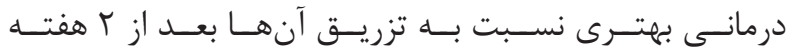

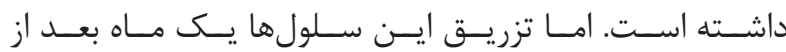

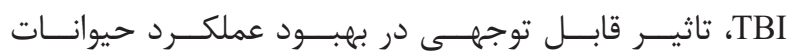

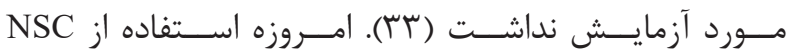

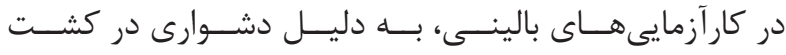

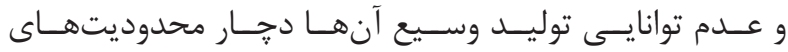

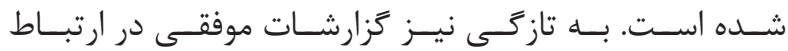

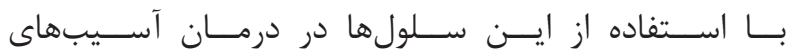

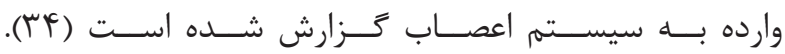

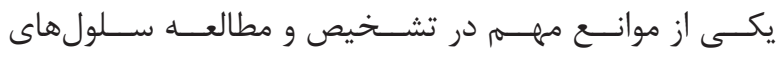

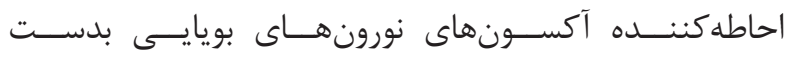

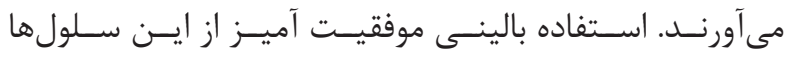

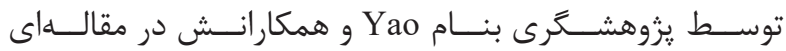

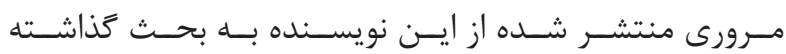

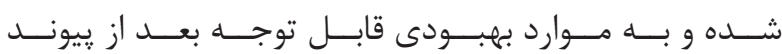

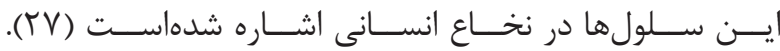

F - سلولهاى مزانشيمى مشتق از بافت اندومتريال رحم (EnSC)

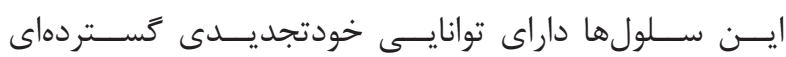

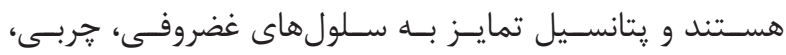

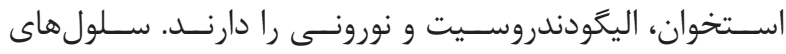

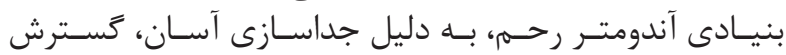

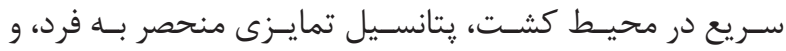

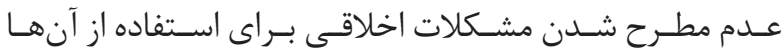

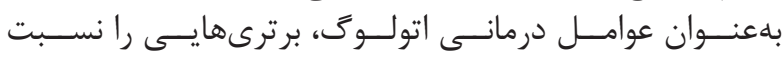

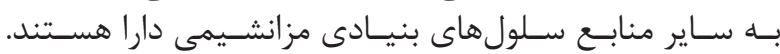

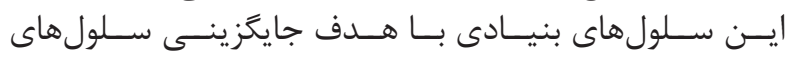

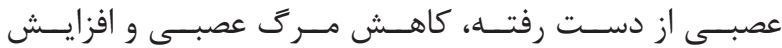

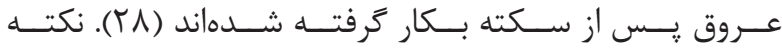

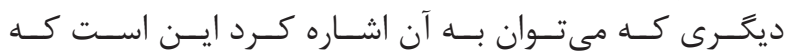

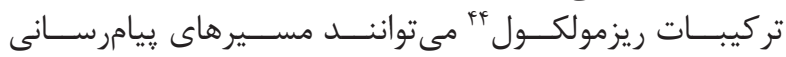

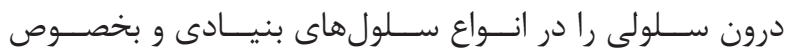

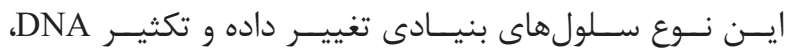

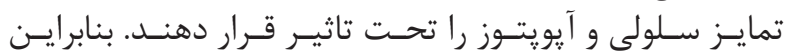

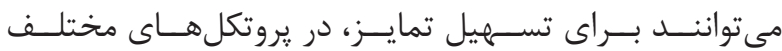

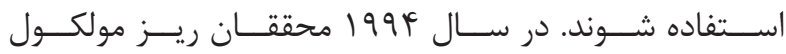

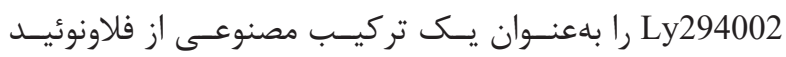

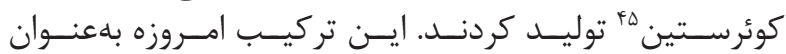

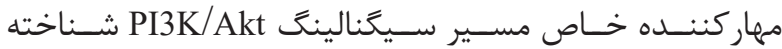

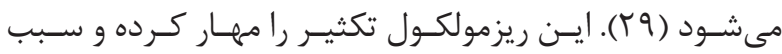

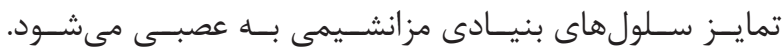

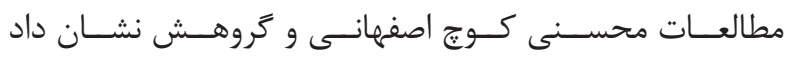

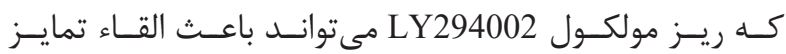

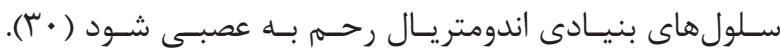

\section{ه- سلول هاى بنيادى عصبى (NSC)}

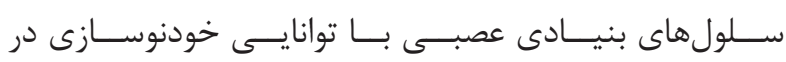

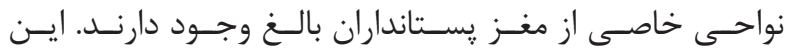

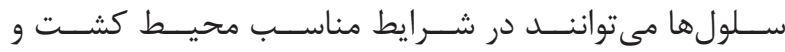

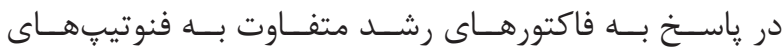

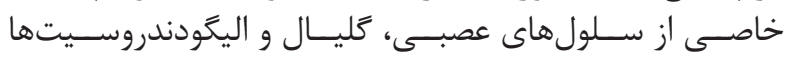

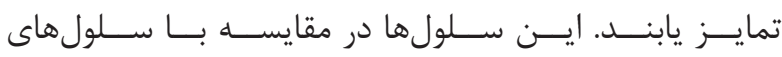

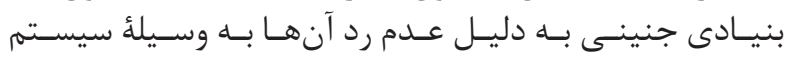

\footnotetext{
${ }^{47}$ Stereotactic

${ }^{48}$ Lateral ventricle

${ }^{49}$ Reynolds \& Weiss

${ }^{50}$ Neurosphere Assay
} 


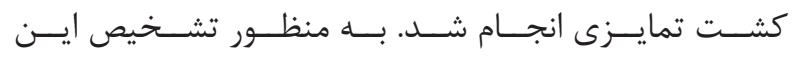

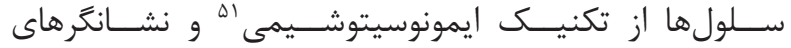

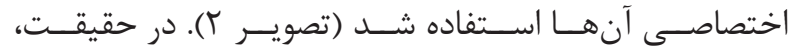

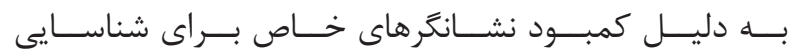

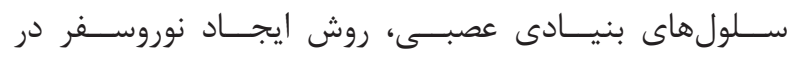

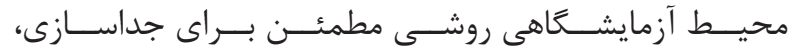

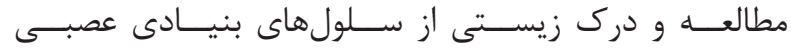

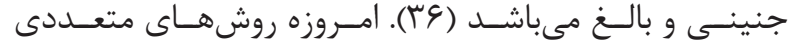

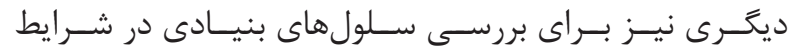

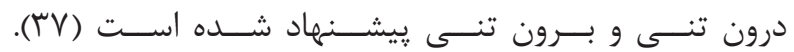

\section{צ- سلولهاى بنيادى «رتوان القايى (iPSC)}

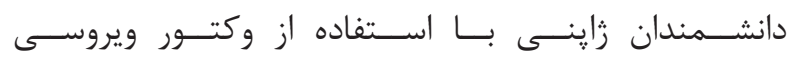

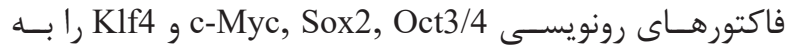

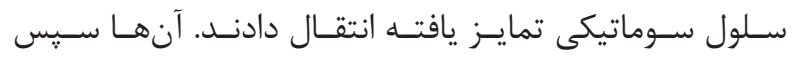

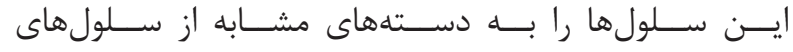

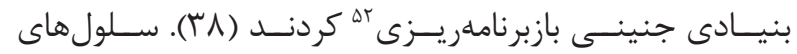

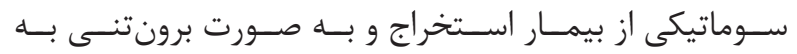

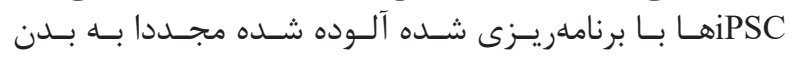

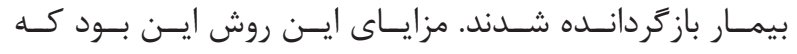

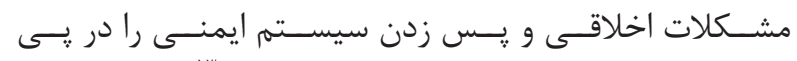

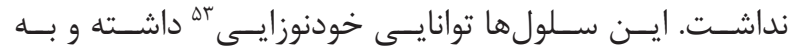

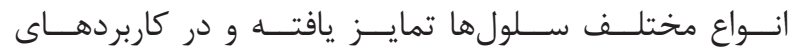

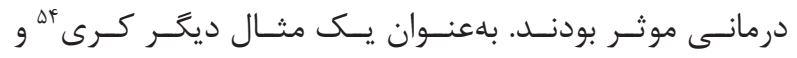

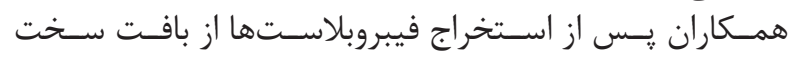

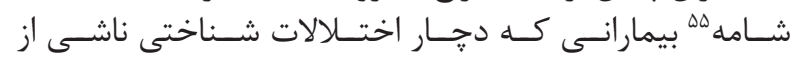

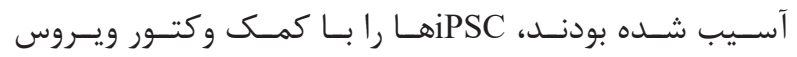

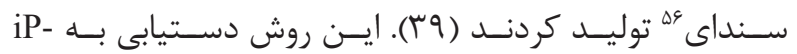

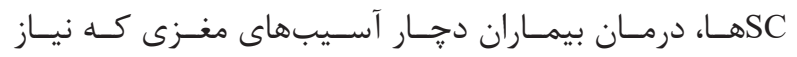

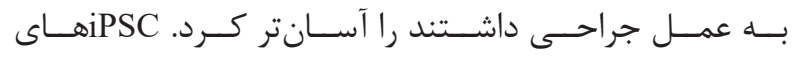

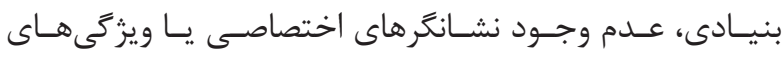

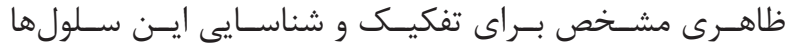

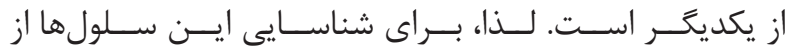

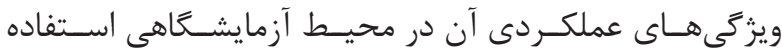

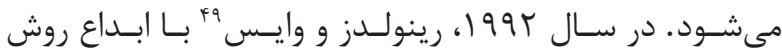

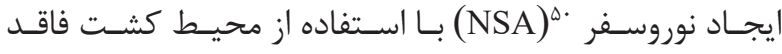

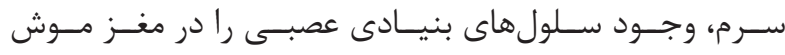

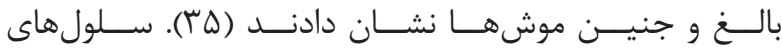

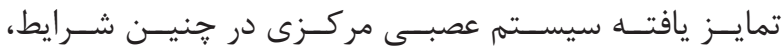

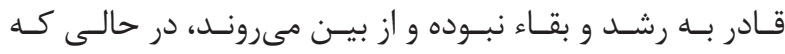

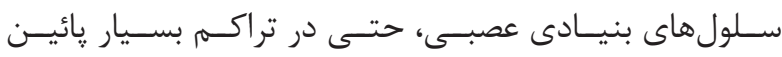

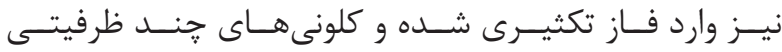

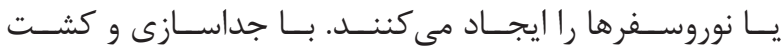

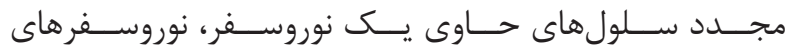

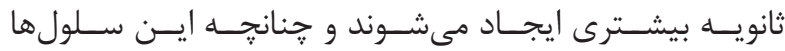

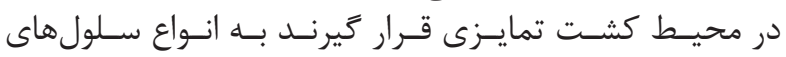

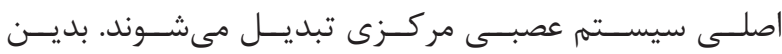

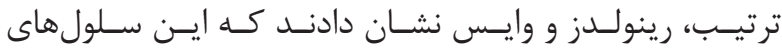

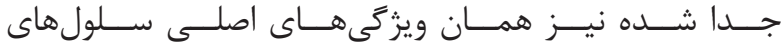

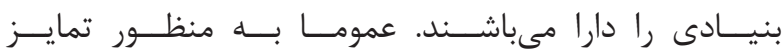

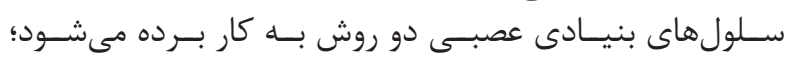

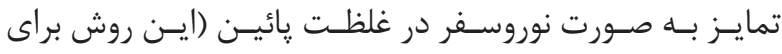

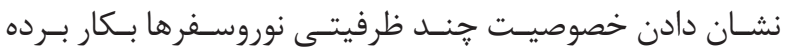

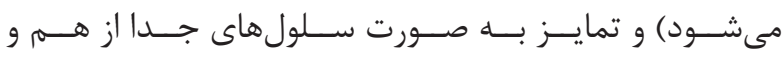

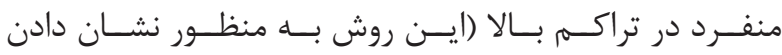

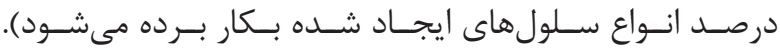

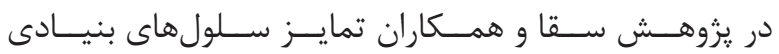

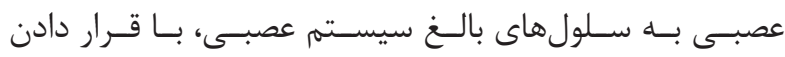

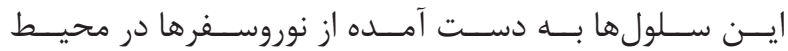

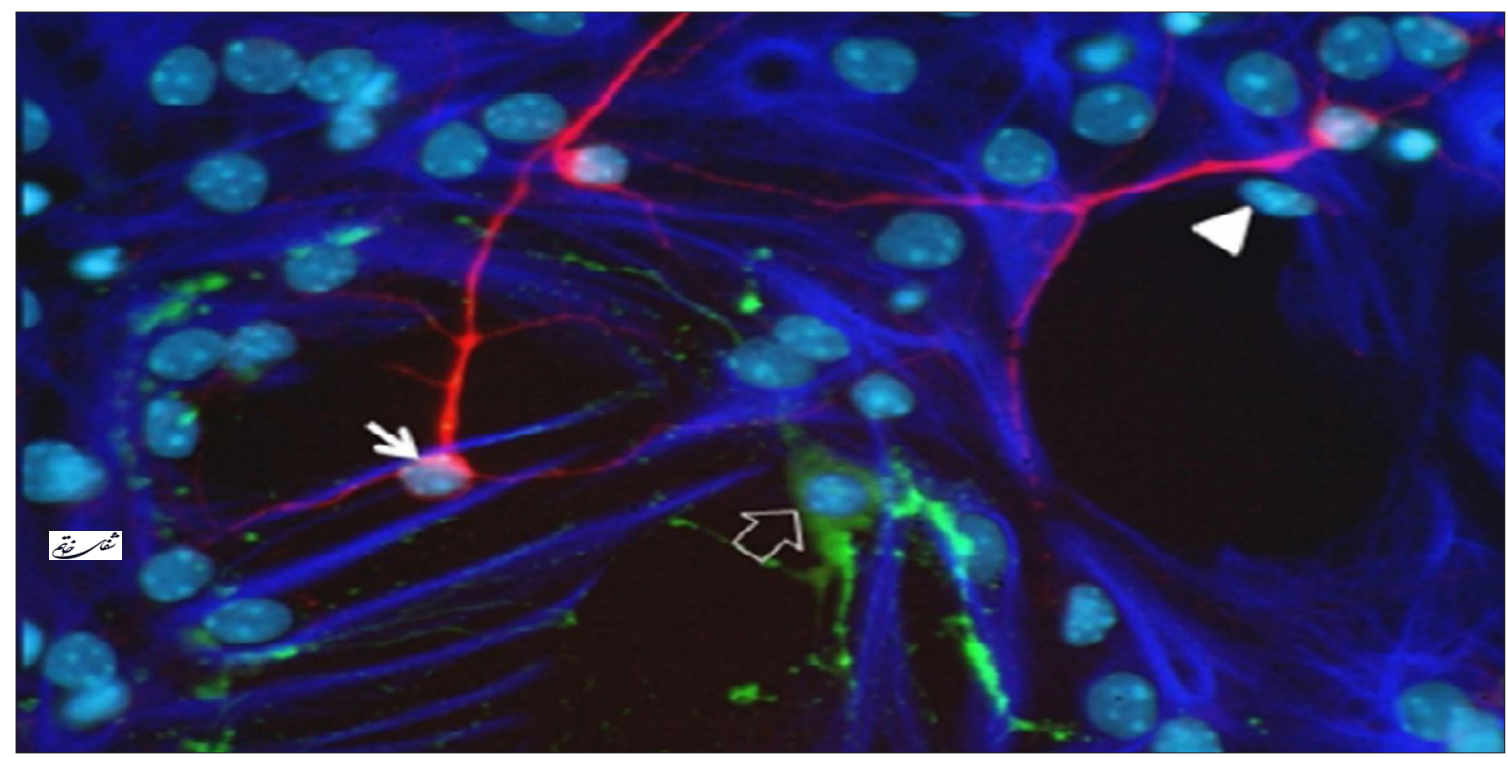

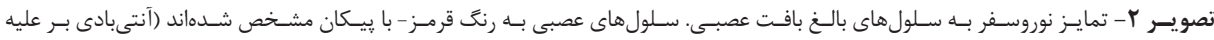
(B-tubulin III

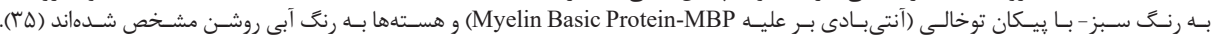

${ }^{51}$ Immunocytochemistry

${ }^{52}$ Reprogram

${ }^{53}$ Self-renewal

${ }^{54}$ Cary

\footnotetext{
${ }^{55}$ Dura mater

${ }^{56}$ Sendai virus

${ }^{57} \mathrm{Gao}$

${ }^{58}$ Lyu
} 


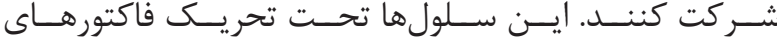

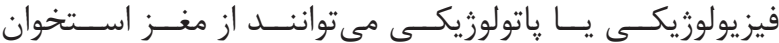

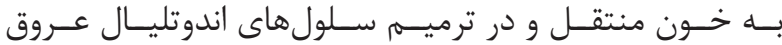

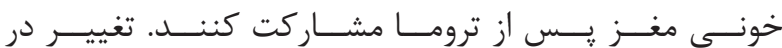

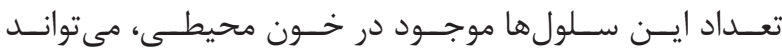

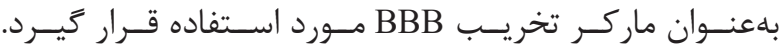

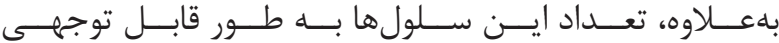

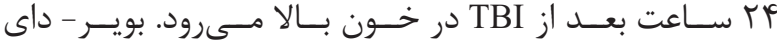

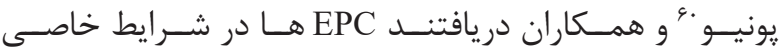

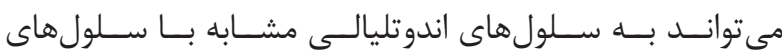

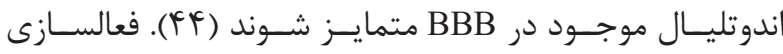

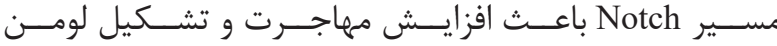

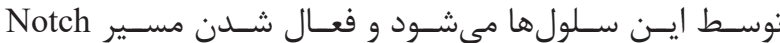

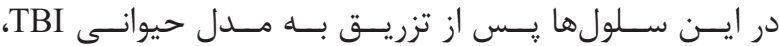

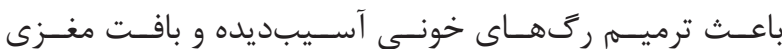

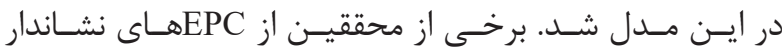

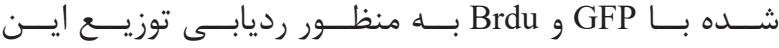

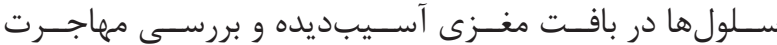

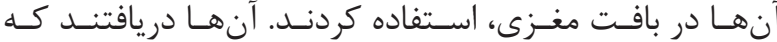

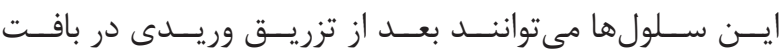

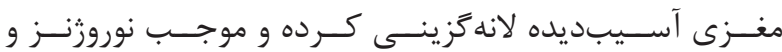

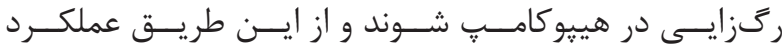

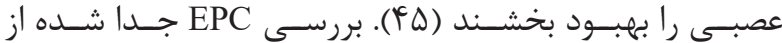

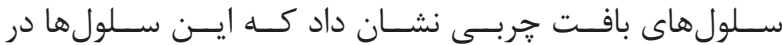

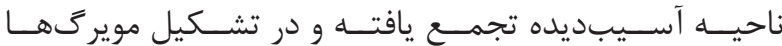

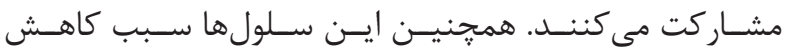

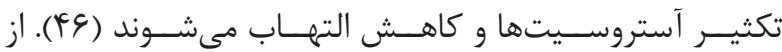

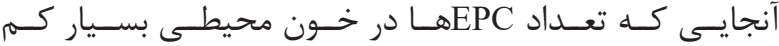

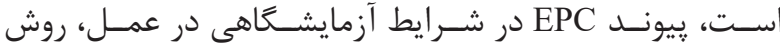

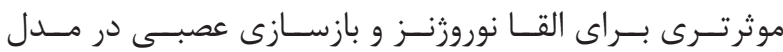

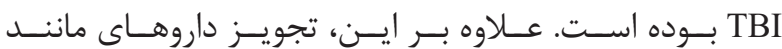

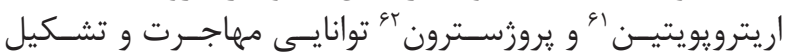

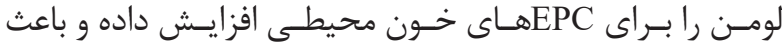

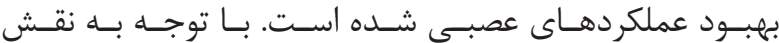

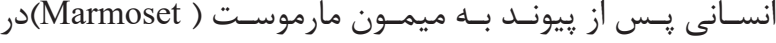

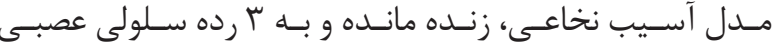

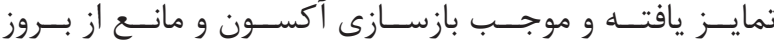

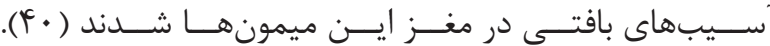

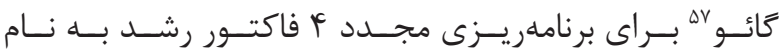

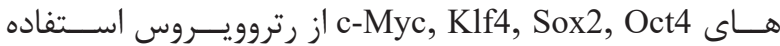

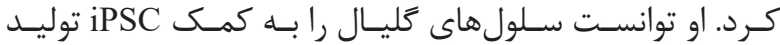

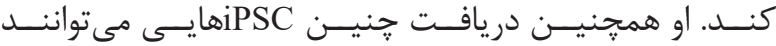

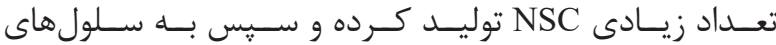

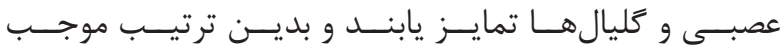

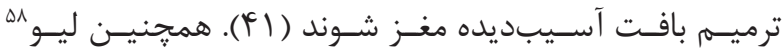

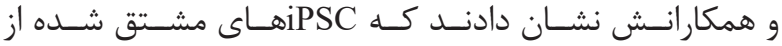

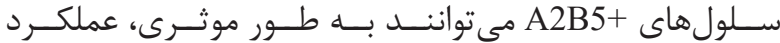

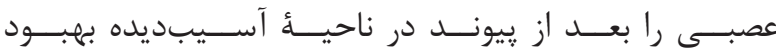

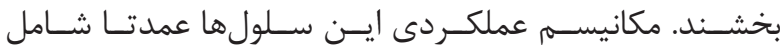

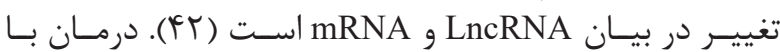

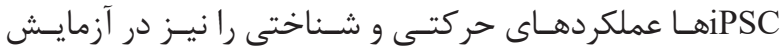

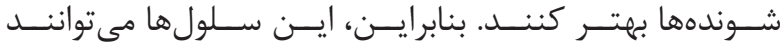

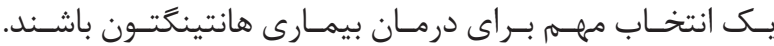

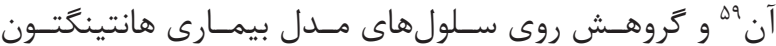

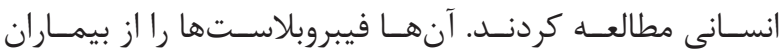

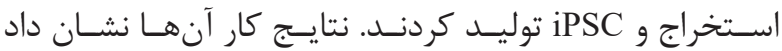

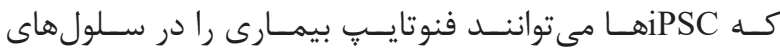

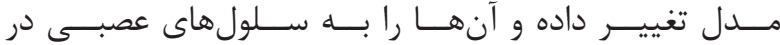

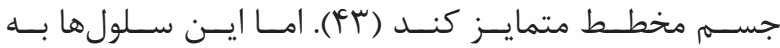

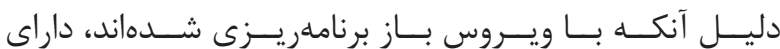

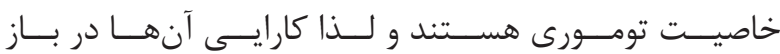

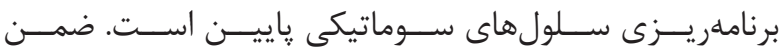

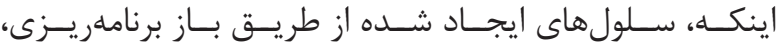

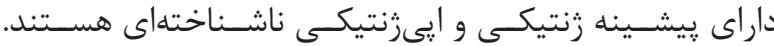

- سلولهاى پيش ساز اندوتليال (EPC) -

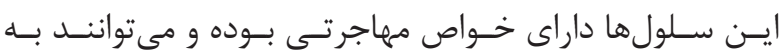

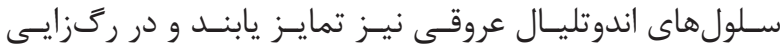

جــدول ا- نـام سـلولهاى بنيـادى و كاربـرد آنها در زمينهُ آسـيب هاى وارده به سيسـتم عصبى بر اسـاس اطلاعـات ارائه شـده در اين مقاله

\begin{tabular}{|c|c|}
\hline مورد استفاده شده & نام سلول بنيادى \\
\hline 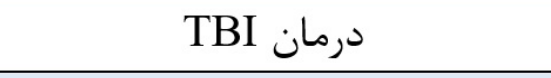 & سلولهاى بنيادى مزانشيمى \\
\hline 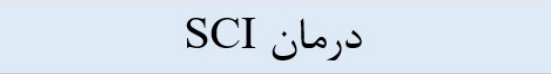 & سلول هاى شوآن \\
\hline درمان SCI انسانى & سلول هاى عصبى بويايى \\
\hline درمان عوارض يس از سكتلُ مغزى & سلولهاى مزانشيمى مشتق از بافت اندومتريال رحم \\
\hline درمان آسيبهاى مغزى & سلولهاى بنيادى عصبى \\
\hline درمان آسيبهاى مغزى & سلولهاى بنيادى برتوان القايى \\
\hline درمان آسيبهاى مغزى ثي نة & سلول هاى ييش ساز اندوتليال \\
\hline
\end{tabular}

${ }^{59} \mathrm{An}$

${ }^{60}$ Boyer-Di Ponio
${ }^{61}$ Erythropoietin

${ }^{62}$ Progesterone 


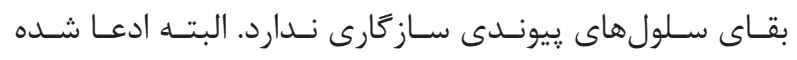

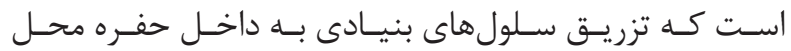

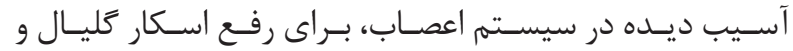

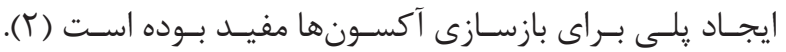

\section{r- زمان مناسب براى ييوند سلولهاى بنيادى}

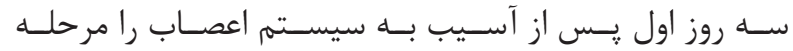

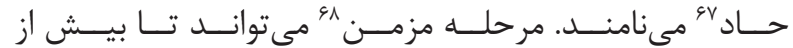

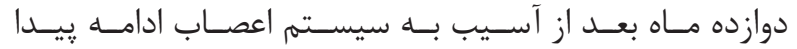

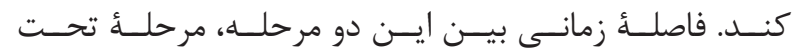

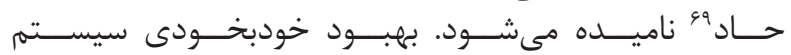

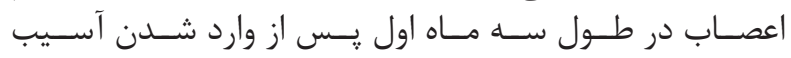

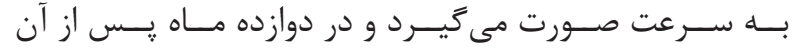

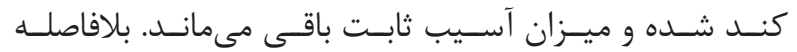

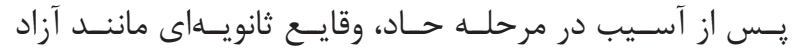

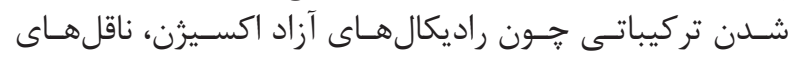

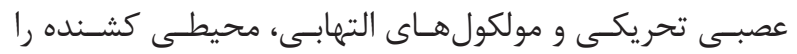

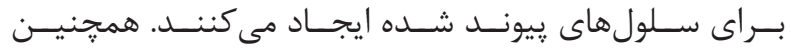

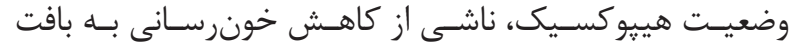

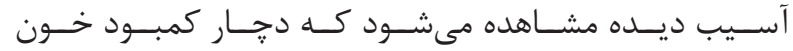

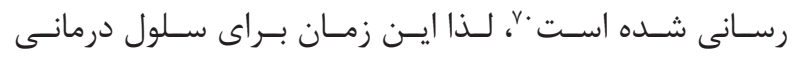

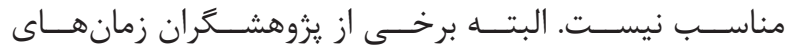

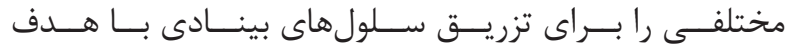

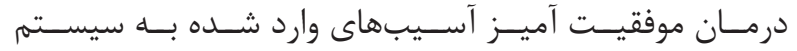

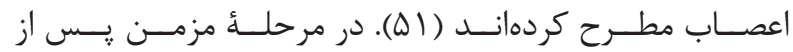

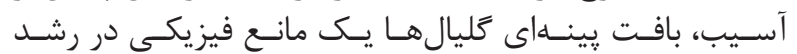

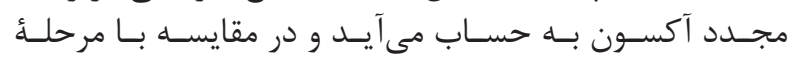

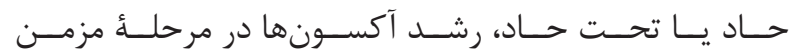

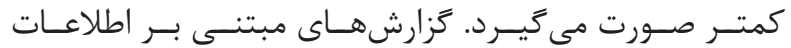

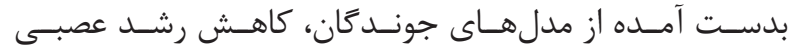

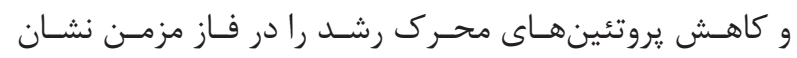

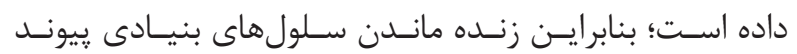

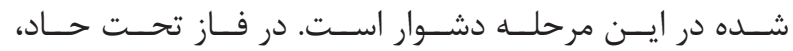

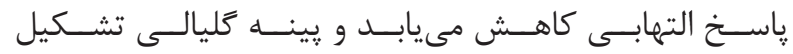

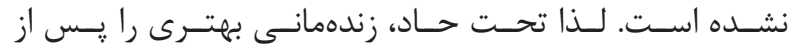

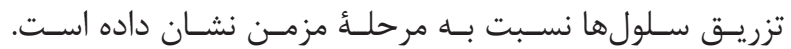

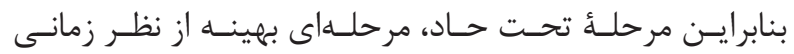

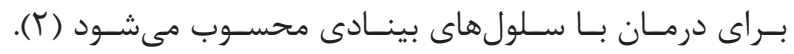

\section{r- تزريق گجندَّانه و تزريق منفرد}

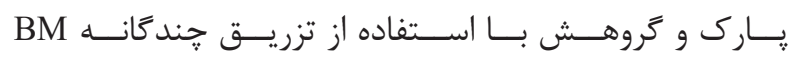

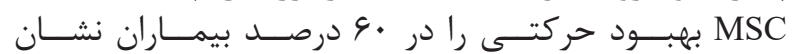

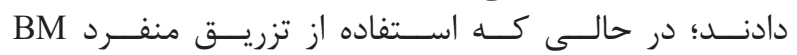

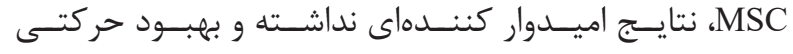

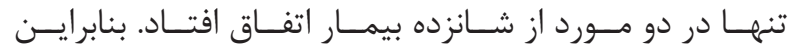

\footnotetext{
${ }^{63}$ Intravenous

${ }^{64}$ Intrathecal

${ }^{65}$ Direct intramedullary

${ }^{66}$ Subarachnoid
}

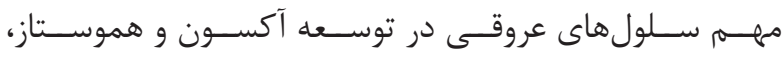

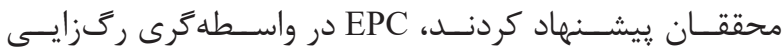

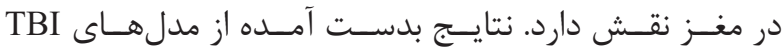

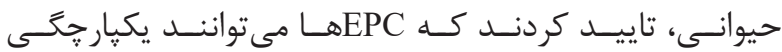

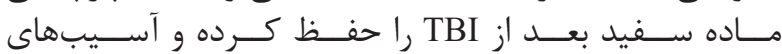

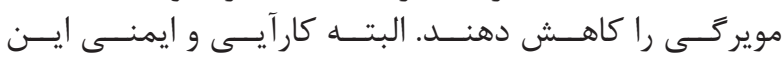

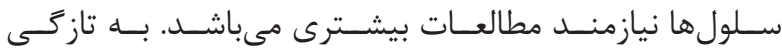

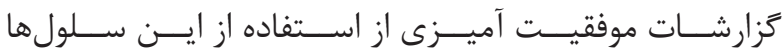

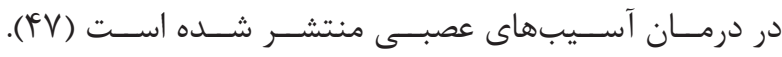

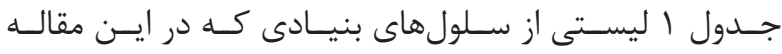

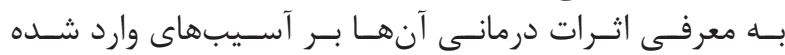

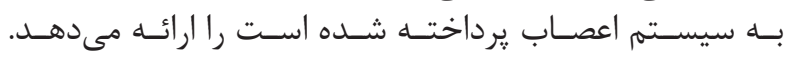

\section{استراتزهاى بهينهسازى اثر درمان با سلولهاى بنيادى}

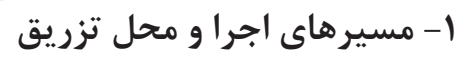

تعييـن مسـير مناسـب بــراى ضييونـد سـلولهاى بنيــادى در

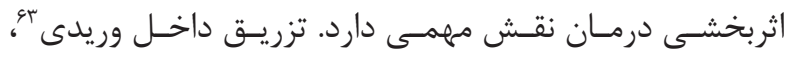

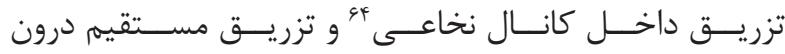

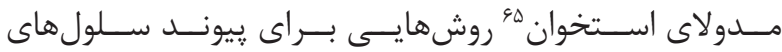

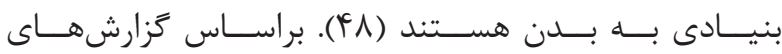

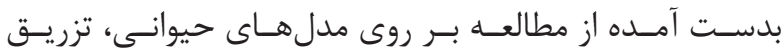

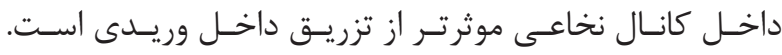

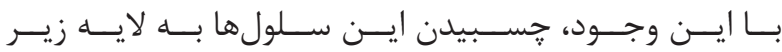

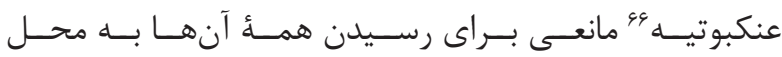

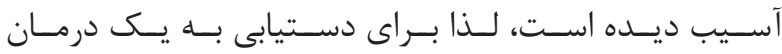

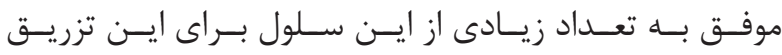

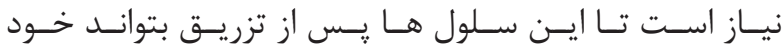

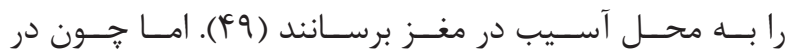

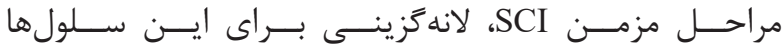

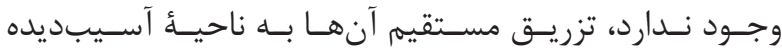

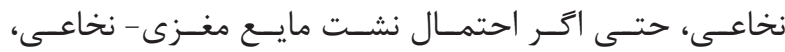

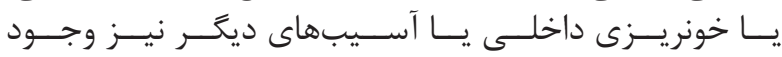

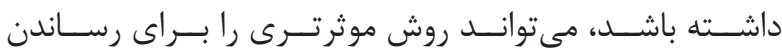

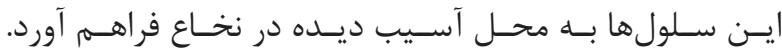

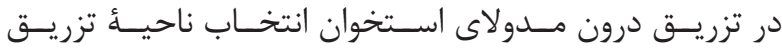

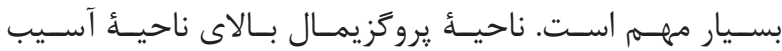

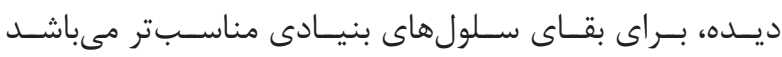

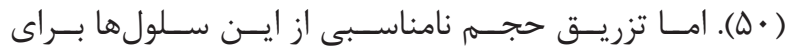

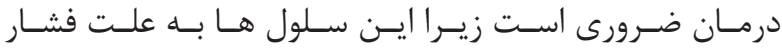

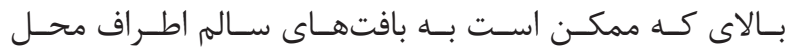

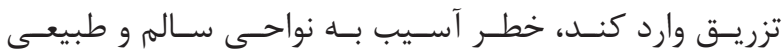

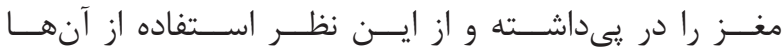

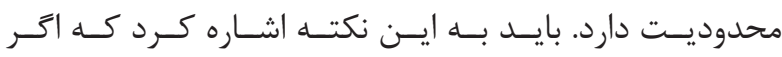

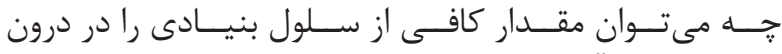

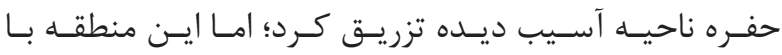

\footnotetext{
${ }^{67}$ Acute

${ }^{68}$ Chronic

${ }^{69}$ Subacute

${ }^{70}$ Perfusion

${ }^{71}$ Chondroitinase
} 


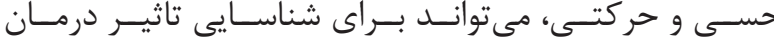

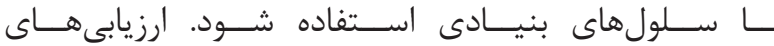

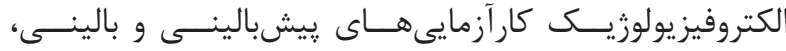

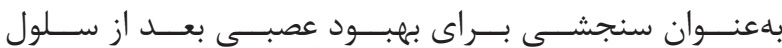

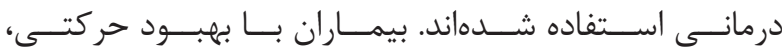

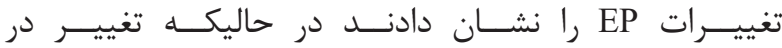

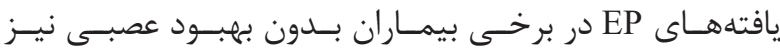

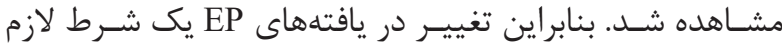

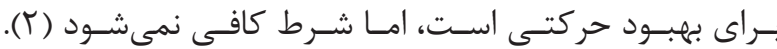
r- مطالعه تصويربردارى تشخيصى

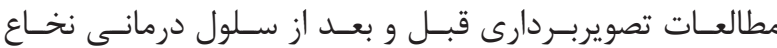

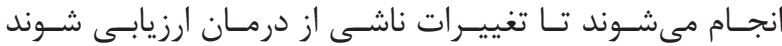

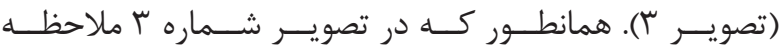

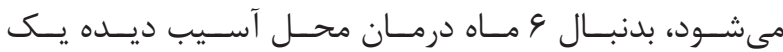

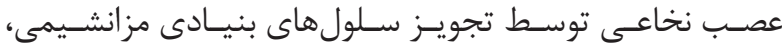

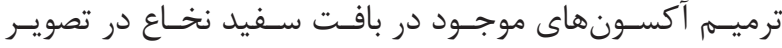

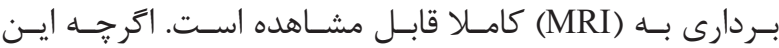

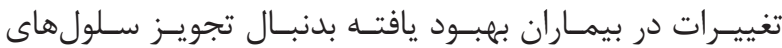

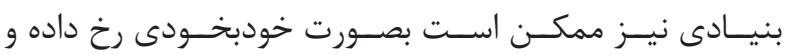

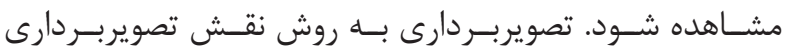
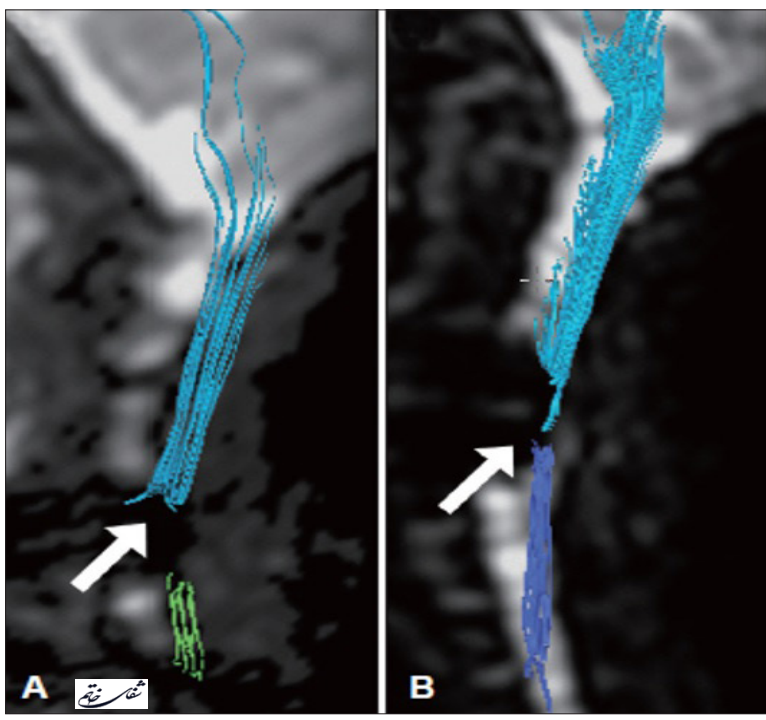

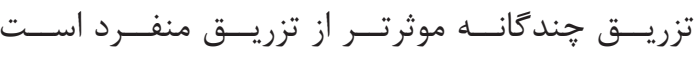

F- استفاده از فاكتور هاى مكمل

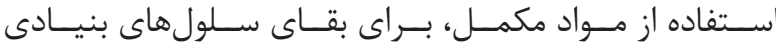

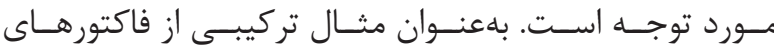

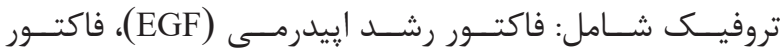

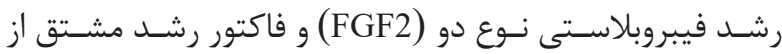

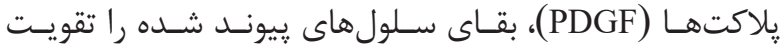

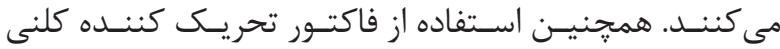

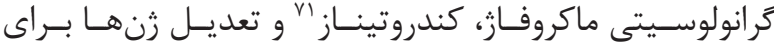

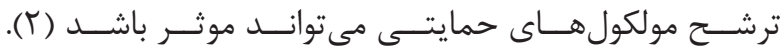

$$
\text { روشهاى براى ارزيابى اثر درمانى إنى }
$$

1- بررسى عصبى و ارزيابى فعاليتهائ درائى روزمره (ADL)

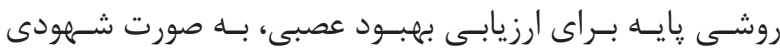

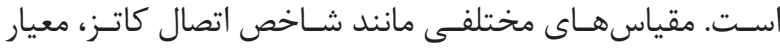

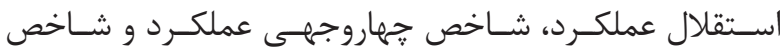

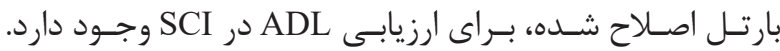

r- مطالعات الكتروفيزيولوزيكى (EP)

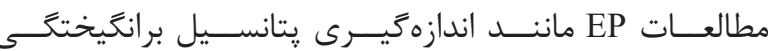

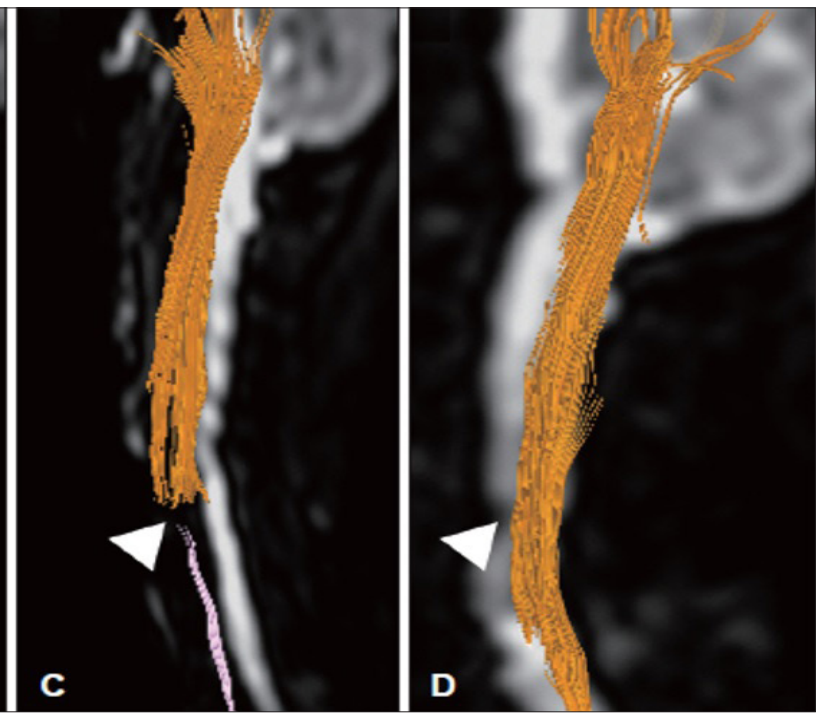

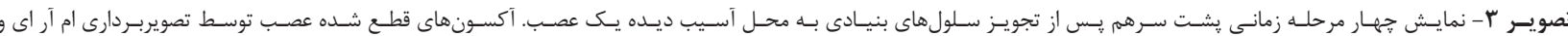

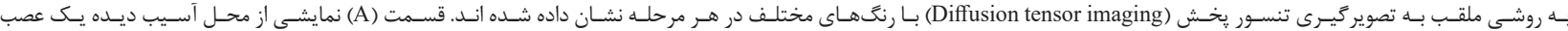

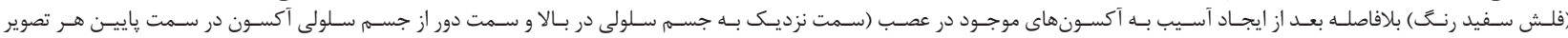

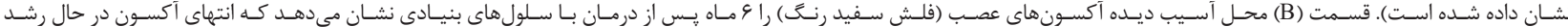

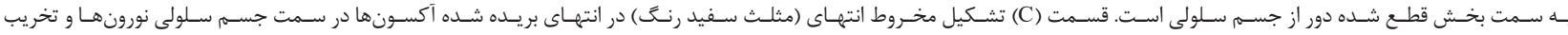

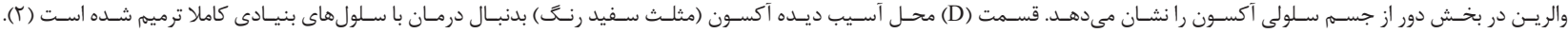

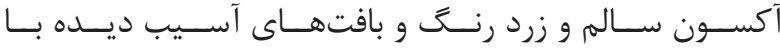

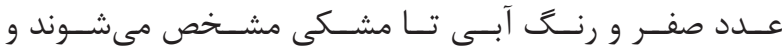

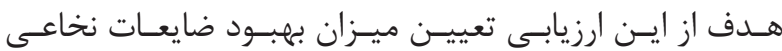

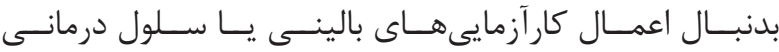

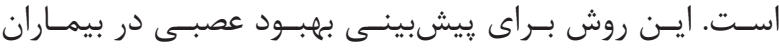

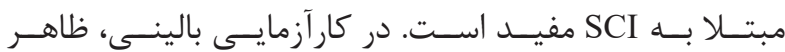

${ }^{72}$ Contrast agent

${ }^{73}$ Positron Emission Tomography

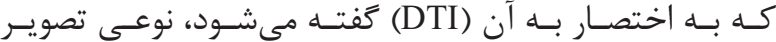

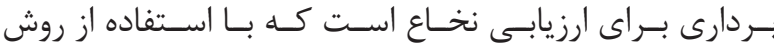

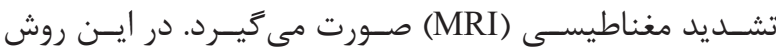

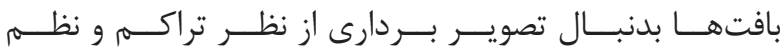

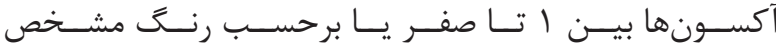

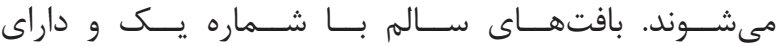

${ }^{74}$ Single-Photon Emission Computed Tomography 


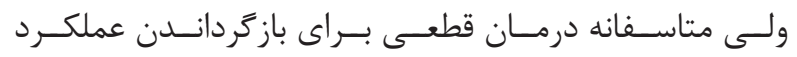

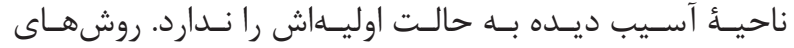

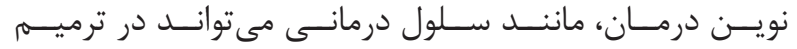

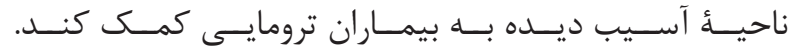

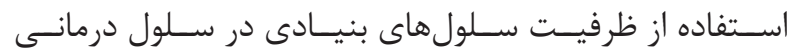

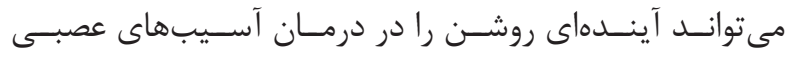

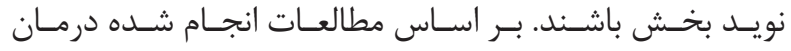

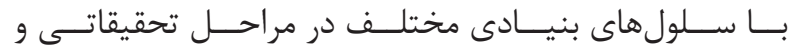

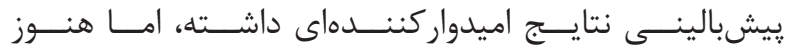

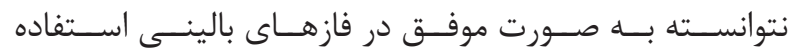

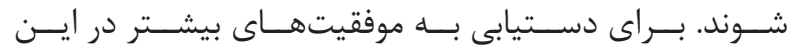

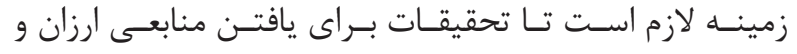

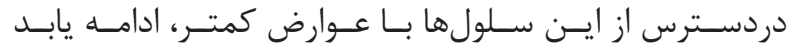

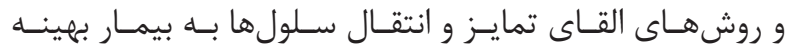

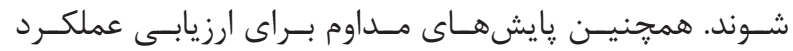

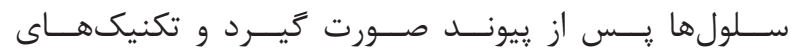

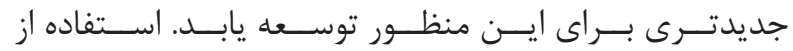

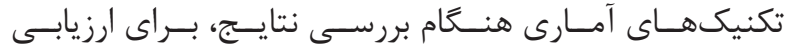

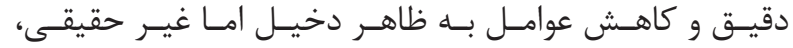

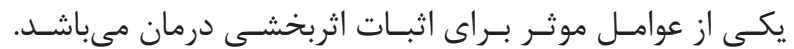

1. Zhou Y, Shao A, $\mathrm{Xu}$ W, Wu H, Deng Y. Advance of Stem Cell Treatment for Traumatic Brain Injury. Front Cell Neurosci 2019; 13(301).

2. Oh SK, Jeon SR. Current Concept of Stem Cell Therapy for Spinal Cord Injury: A Review. Korean J Neurotrauma. 2016; 12(2): 40-6.

3. Seghatoleslam M, Hosseini M. Potential of Stem Cells in the Treatment of Nervous System Disorders. Neurosci. J. Shefaye Khatam. 2015; 3(1): 99-114.

4. Chou DK, Henion TR, Jungalwala FB. Regulation of expression of sulfoglucuronyl carbohydrate (HNK-1), Amphoterin and RAGE in retinoic acid-differentiated P19 embryonal carcinoma cells. J Neurochem. 2003; 86(4): 917-31.

5. Martin GR, Evans MJ. Multiple differentiation of clonal teratocarcinoma stem cells following embryoid body formation in vitro. Cell. 1975; 6(4): 467-74.

6. Bakhshalizadeh S, Esmaeili F, Houshmand F, Shirzad H, Saedi M. Effects of selegiline, a monoamine oxidase B inhibitor, on differentiation of P19 embryonal carcinoma stem cells, into neuron-like cells. In Vitro Cell Dev Biol Anim. 2011; 47(8): 550-7.

7. Hattori $\mathrm{N}$, Nomoto $\mathrm{H}$, Mishima $\mathrm{S}$, Inagaki $\mathrm{S}$, Goto M, Sako M, et al. Identification of AMP N1oxide in royal jelly as a component neurotrophic toward cultured rat pheochromocytoma PC12 cells. Biosci Biotechnol Biochem. 2006; 70(4): 897-906.

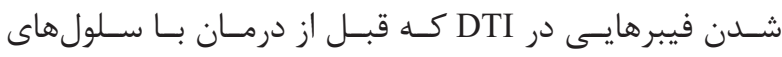

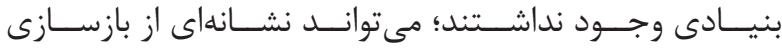

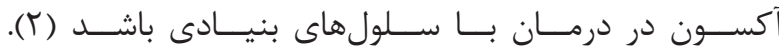
F - تكنيك نشاندار كردن در تصويربردارى

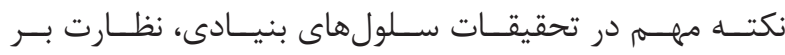

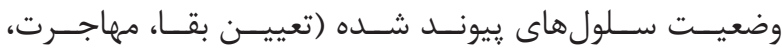

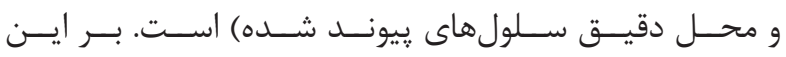

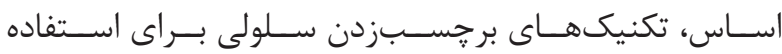

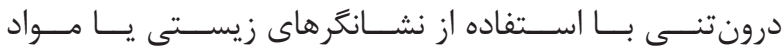

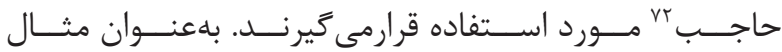

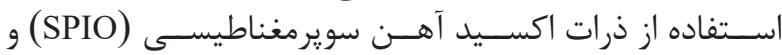

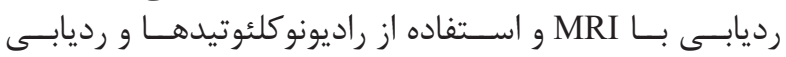

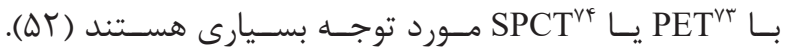
نتيجه گيرى

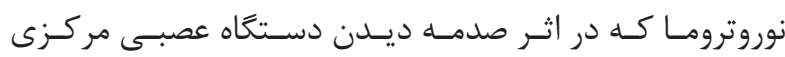

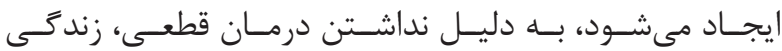

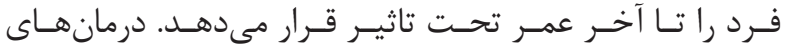

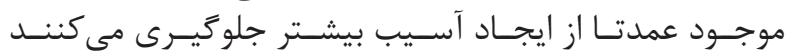

8. Ebrahimie M, Asgharzadih S, Shirzad Ebrahimie N, Hoseini M, kakolake MK, et al. An Evaluation of the Influence of Royal Jelly on Differentiation of Stem Cells into Neuronal Cells Invitro. J Babol Univ Med Sci. 2016; 18: 38-44.

9. Bedi SS, Walker PA, Shah SK, Jimenez F, Thomas CP, Smith $\mathrm{P}$, et al. Autologous bone marrow mononuclear cells therapy attenuates activated microglial/macrophage response and improves spatial learning after traumatic braininjury.JTraumaAcuteCareSurg. 2013;75(3):410-6.

10. Sanchez-Ramos J, Song S, Cardozo-Pelaez F, Hazzi C, Stedeford T, Willing A, et al. Adult Bone Marrow Stromal Cells Differentiate into Neural Cells in Vitro. Exp Neurol. 2000; 164(2): 247-56.

11. Woodbury D, SchwarzEJ, ProckopDJ, BlackIB. Adult rat and human bone marrow stromal cells differentiate into neurons. J Neurosci Res. 2000; 61(4): 364-70.

12. Nemati SH, Zare Mehrjerdi N, Baharvand H. Differentiation of human bone marrow mesenchymal stem cells to neural- like cells in vitro. Tehran Univ Med J (TUMJ) 2009; 67(8).

13. Wang S, Kan Q, Sun Y, Han R, Zhang G, Peng T, et al. Caveolin-1 regulates neural differentiation of rat bone mesenchymal stem cells into neurons by modulating Notch signaling. Int J Dev Neurosci. 2013; 31(1): 30-5.

14. Zhang R, Liu Y, Yan K, Chen L, Chen XR, Li P, 
et al. Anti-inflammatory and immunomodulatory mechanisms of mesenchymal stem cell transplantation in experimental traumatic brain injury. J Neuroinflammation. 2013; 10: 106.

15. Park JH, Kim DY, Sung IY, Choi GH, Jeon $\mathrm{MH}$, Kim KK, et al. Long-term results of spinal cord injury therapy using mesenchymal stem cells derived from bone marrow in humans. Neurosurgery. 2012; 70(5): 1238-47; discussion 47.

16. Adib S, Tirahi T, Taheri T. Remyelination of Demyelinated Rat Spinal Cord Model by Transplanting Neural Stem Cells. Pathobiology Research. 2012; 15(2): 23-34.

17. Guo S, Zhen Y, Wang A. Transplantation of bone mesenchymal stem cells promotes angiogenesis and improvesneurologicalfunctionaftertraumaticbraininjury in mouse. Neuropsychiatr Dis Treat. 2017; 13: 2757-65.

18. Shi X, Bai Y, Zhang G, Liu Y, Xiao H, Liu X, et al. Effects of over-expression of SOD2 in bone marrow-derived mesenchymal stem cells on traumatic brain injury. Cell Tissue Res. 2018; 372(1): 67-75.

19. Djouad F, Plence P, Bony C, Tropel P, Apparailly $\mathrm{F}$, Sany $\mathrm{J}$, et al. Immunosuppressive effect of mesenchymal stem cells favors tumor growth in allogeneic animals. Blood. 2003; 102(10): 3837-44.

20. Zhang ZX, Guan LX, Zhang K, Zhang Q, Dai LJ. A combined procedure to deliver autologous mesenchymal stromal cells to patients with traumatic brain injury. Cytotherapy. 2008; 10(2): 134-9.

21. Wang Z, Luo Y, Chen L, Liang W. Safety of neural stem cell transplantation in patients with severe traumatic brain injury. Exp Ther Med. 2017; 13(6): 3613-8.

22. Gold EM, Su D, López-Velázquez L, Haus DL, Perez H, Lacuesta GA, et al. Functional assessment of long-term deficits in rodent models of traumatic brain injury. Regen Med. 2013; 8(4): 483-516.

23. Zhang Y, Chopp M, Meng Y, Katakowski M, Xin H, Mahmood A, et al. Effect of exosomes derived from multipluripotent mesenchymal stromal cells on functional recovery and neurovascular plasticity in rats after traumatic brain injury. J Neurosurg. 2015; 122(4): 856-67.

24. Zhang Y, Chopp M, Zhang ZG, Katakowski M, Xin $\mathrm{H}$, Qu C, et al. Systemic administration of cell-free exosomes generated by human bone marrow derived mesenchymal stem cells cultured under 2D and 3D conditions improves functional recovery in rats after traumatic brain injury. Neurochem Int. 2017; 111: 69-81.
25. Saberi H, Firouzi M, Habibi Z, Moshayedi P, Aghayan HR, Arjmand B, et al. Safety of intramedullary Schwann cell transplantation for postrehabilitation spinal cord injuries: 2-year followup of 33 cases. J Neurosurg Spine. 2011; 15(5): 515-25.

26. Anna Z, Katarzyna JW, Joanna C, Barczewska M, Joanna W, Wojciech M. Therapeutic Potential of Olfactory Ensheathing Cells and Mesenchymal Stem Cells in Spinal Cord Injuries. Stem cells international. 2017; 2017: 3978595.

27. Yao R, Murtaza M, Velasquez JT, Todorovic M, Rayfield A, Ekberg J, et al. Olfactory Ensheathing Cells for Spinal Cord Injury:Sniffing Out the Issues. Cell Transplantation. 2018; 27(6): 879-89.

28. Mutlu L, Hufnagel D, Taylor HS. The endometrium as a source of mesenchymal stem cells for regenerative medicine. Biol Reprod. 2015 Jun;92(6):138. doi: 10.1095/biolreprod.114.126771.

29. Vlahos CJ, Matter WF, Hui KY, Brown RF. A specific inhibitor of phosphatidylinositol 3-kinase, 2-(4-morpholinyl)-8-phenyl-4H-1-benzopyran-4one (LY294002). J Biol Chem. 1994; 269(7): 5241-8.

30. Mohseni kouchesfahani H, Ebrahimi Barough S, Ai j, Anbar H. Endometrial stem cells differentiation into neural cells by LY294002 small molecule. Koomesh. 2016; 18(1): 62-70.

31. Haus DL, López-Velázquez L, Gold EM, Cunningham KM, Perez $\mathrm{H}$, Anderson AJ, et al. Transplantation of human neural stem cells restores cognition in an immunodeficient rodent model of traumatic brain injury. Exp Neurol. 2016; 281: 1-16.

32. Philips MF, Mattiasson G, Wieloch T, Björklund A, Johansson BB, Tomasevic G, et al. Neuroprotective and behavioral efficacy of nerve growth factor-transfected hippocampalprogenitorcelltransplantsafterexperimental traumatic brain injury. J Neurosurg. 2001; 94(5): 765-74.

33. Zhang C, Saatman KE, Royo NC, Soltesz KM, Millard M, Schouten JW, et al. Delayed transplantation of human neurons following brain injury in rats: a long-term graft survival and behavior study. J Neurotrauma. 2005; 22(12): 1456-74.

34. Clervius H, Baig M, Mahavadi A, Gajavelli S. Human neural stem cell transplants to address multiple pathologies associated with traumatic brain injury. Neural Regen Res. 2019 Oct;14(10):1699$1700 . \quad$ doi: $\quad 10.4103 / 1673-5374.255620$.

35. Reynolds BA, Weiss S. Generation of neurons 
and astrocytes from isolated cells of the adult mammalian central nervous system. Science (New York, NY). 1992; 255(5052): 1707-10.

36. Golmohammadi MG, Sagha M, Azari H, Najafzadeh N. Isolation of Neural Stem and Progenitor Cells from the Adult Mouse Brain Using the Neurosphere Assay. J Ardabil Univ Med Sci. 2011; 11(3): 246-58.

37. Biswas S, Chung SH, Jiang P, Dehghan S, Deng W. Development of glial restricted human neural stem cells for oligodendrocyte differentiation in vitro and in vivo. Sci Rep. 2019 Jun 21;9(1):9013.

38. Takahashi K, Yamanaka S. Induction of pluripotent stem cells from mouse embryonic and adult fibroblast cultures by defined factors. Cell. 2006; 126(4): 663-76.

39. Cary WA, Hori CN, Pham MT, Nacey CA, McGee JL, Hamou M, et al. Efficient Generation of Induced Pluripotent Stem and Neural Progenitor Cells From Acutely Harvested Dura Mater Obtained During Ventriculoperitoneal Shunt Surgery. World Neurosurg. 2015; 84(5): 1256-66.

40. Kobayashi Y, Okada Y, Itakura G, Iwai H, Nishimura S, Yasuda A, et al. Pre-evaluated safe human iPSC-derived neural stem cells promote functional recovery after spinal cord injury in common marmoset without tumorigenicity. PloS one. 2012; 7(12): e52787.

41. Gao X, Wang X, Xiong W, Chen J. In vivo reprogramming reactive glia into iPSCs to produce new neurons in the cortex following traumatic brain injury. Sci Rep. 2016; 6: 22490.

42. Lyu Q, Zhang ZB, Fu SJ, Xiong LL, Liu J, Wang TH. Microarray Expression Profile of lncRNAs and mRNAs in Rats with Traumatic Brain Injury after A2B5+ Cell Transplantation. Cell Transplant. 2017; 26(10): 1622-35.

43. An MC, Zhang N, Scott G, Montoro D, Wittkop T, Mooney S, et al. Genetic correction of Huntington's disease phenotypes in induced pluripotent stem cells. Cell stem cell. 2012; 11(2): 253-63.
44. Ponio JB-D, El-Ayoubi F, Glacial F, Ganeshamoorthy K, Driancourt C, Godet M, et al. Instruction of Circulating Endothelial Progenitors In Vitro towards Specialized Blood-Brain Barrier and Arterial Phenotypes. PloS One. 2014; 9(1): e84179.

45. Guo X-b, Deng X, Wei Y. Homing of Cultured EndothelialProgenitorCells and TheirEffecton Traumatic Brain Injury in Rat Model. Sci rep. 2017; 7(1): 4164.

46. Xue S, Zhang H-t, Zhang P, Luo J, Chen $\mathrm{Z}-\mathrm{z}$, Jang $\mathrm{X}-\mathrm{d}$, et al. Functional endothelial progenitor cells derived from adipose tissue show beneficial effect on cell therapy of traumatic brain injury. Neurosci Lett. 2010; 473(3): 186-91.

47. Kamei N, Atesok K, Ochi M. The Use of Endothelial Progenitor Cells for the Regeneration of Musculoskeletal and Neural Tissues. Stem Cells Int. 2017;2017:1960804. doi: 10.1155/2017/1960804. Epub 2017 Mar 28. PMID: 28458693; PMCID: PMC5387841.

48. Levi AD, Okonkwo DO, Park P, Jenkins AL 3rd, Kurpad SN, Parr AM, Ganju A, Aarabi B, Kim D, Casha $\mathrm{S}$, Fehlings MG, Harrop JS, Anderson KD, Gage A, Hsieh J, Huhn S, Curt A, Guzman R. Emerging Safety of Intramedullary Transplantation of Human Neural Stem Cells in Chronic Cervical and Thoracic Spinal Cord Injury. Neurosurgery. 2018 Apr 1;82(4):562-75.

49. Silvestro S, Bramanti P, Trubiani O, Mazzon E. Stem Cells Therapy for Spinal Cord Injury: An Overview of Clinical Trials. Int J Mol Sci. 2020 Jan 19;21(2): 659.

50. Gao L, Peng Y, Xu W, He P, Li T, Lu X, Chen G. Progress in Stem Cell Therapy for Spinal Cord Injury. Stem Cells Int. 2020 Nov 5; 2020: 2853650.

51. Shao A, Tu S, Lu J. et al. Crosstalk between stem cell and spinal cord injury: pathophysiology and treatment strategies. Stem Cell Res Ther 2019; 10: 238.

52. Bulte JWM, Kraitchman DL. Iron oxide MR contrast agents for molecular and cellular imaging. NMR Biomed. 2004; 17(7): 484-99 